\title{
Grain size effects in donor doped lead zirconate titanate ceramics
}

Cite as: J. Appl. Phys. 128, 214105 (2020); https://doi.org/10.1063/5.0029659

Submitted: 15 September 2020 . Accepted: 17 November 2020 . Published Online: 07 December 2020

(iD) Gunnar Picht, (D) Neamul H. Khansur, Kyle G. Webber, (D) Hans Kungl, Michael J. Hoffmann, and (iD) Manuel Hinterstein

\section{COLLECTIONS}

Paper published as part of the special topic on Domains and Domain Walls in Ferroic Materials DDWFM2021
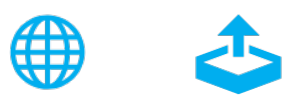

View Online

\section{ARTICLES YOU MAY BE INTERESTED IN}

$\mathrm{BaTiO}_{3}$-based piezoelectrics: Fundamentals, current status, and perspectives

Applied Physics Reviews 4, 041305 (2017); https://doi.org/10.1063/1.4990046

Abrupt change in domain switching behavior within tetragonal phase regime of

(x) $\mathrm{Na}_{1 / 2} \mathrm{Bi}_{1 / 2} \mathrm{TiO}_{3}-(1-\mathrm{x}) \mathrm{K}_{1 / 2} \mathrm{Bi}_{1 / 2} \mathrm{TiO}_{3}$

Journal of Applied Physics 128, 204102 (2020); https://doi.org/10.1063/5.0030195

Electric-field-induced strain of ( $\mathrm{Li}, \mathrm{Na}, \mathrm{K}) \mathrm{NbO}_{3}$-based multilayered piezoceramics under electromechanical loading

Journal of Applied Physics 128, 244101 (2020); https://doi.org/10.1063/5.0029615

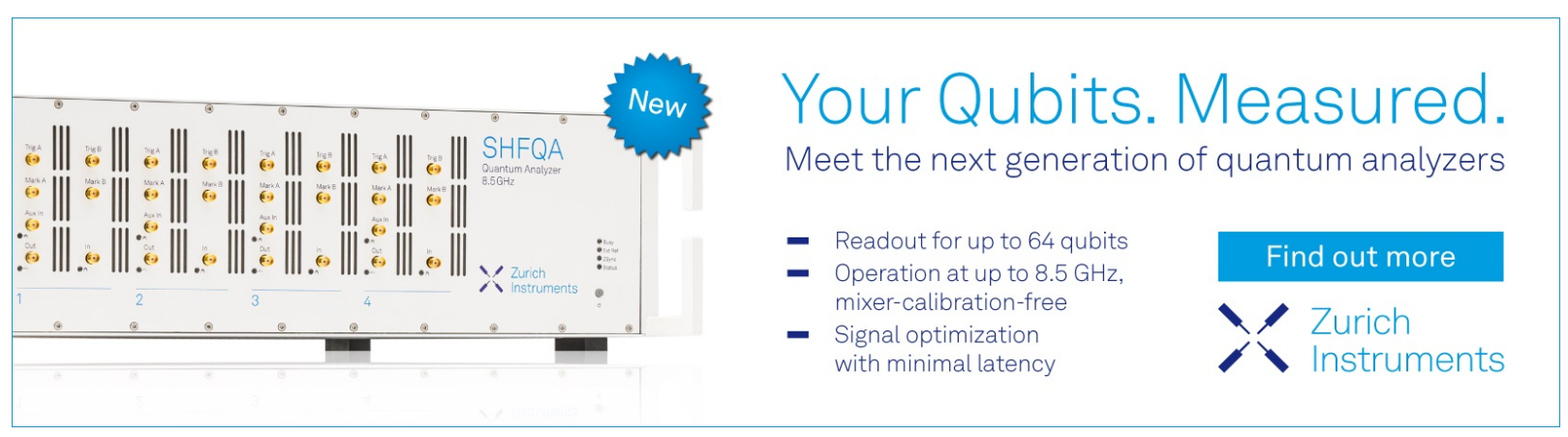




\title{
Grain size effects in donor doped lead zirconate titanate ceramics
}

\author{
Cite as: J. Appl. Phys. 128, 214105 (2020); doi: 10.1063/5.0029659 \\ Submitted: 15 September 2020 - Accepted: 17 November 2020 . \\ Published Online: 7 December 2020
}

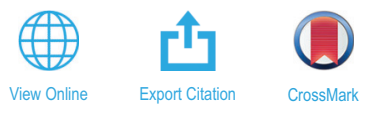

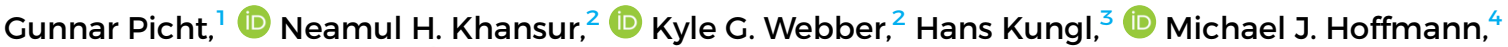
and Manuel Hinterstein ${ }^{4, a)}$ (iD

\author{
AFFILIATIONS \\ ${ }^{7}$ Robert Bosch $\mathrm{GmbH}$, Corporate Sector Research and Advance Engineering Applied Research Materials, Robert-Bosch-Campus \\ 171272, Renningen, Germany \\ ${ }^{2}$ Department of Materials Science and Engineering, Friedrich-Alexander-Universität Erlangen-Nürnberg (FAU), Martensstraße 5 \\ 91508, Erlangen, Germany \\ ${ }^{3}$ Forschungzentrum Jülich, Institute of Energy and Climate Research, Fundamental Electrochemistry (IEK-9), \\ Jülich 52425, Germany \\ ${ }^{4}$ Institute of Applied Materials, Ceramic Materials and Technologies, Karlsruhe Institute of Technology 76131, Karlsruhe, Germany
}

Note: This paper is part of the Special Topic on Domains and Domain Walls in Ferroic Materials

a) Author to whom correspondence should be addressed: manuel.hinterstein@kit.edu

\begin{abstract}
The ferroelectric, ferroelastic, and dielectric properties as well as the crystal structure were investigated for polycrystalline donor doped lead zirconate titanate (PZT) with grain sizes ranging from 0.25 to $5 \mu \mathrm{m}$, which were prepared using a novel zirconium titanium hydrate precursor $(\mathrm{ZTH})$ with a specific surface area of $310 \mathrm{~m}^{2} / \mathrm{g}$. Piezoforce microscopy was used to investigate the change in the domain structure, revealing a change in the domain configuration from a complex 3D structure to a simple lamellar domain formation at a $1 \mu \mathrm{m}$ grain size that corresponded to a rapidly increasing internal mechanical stress observed with in situ synchrotron x-ray experiments. The correlation between the change in domain configuration, increasing internal stresses, effects of poling on the crystal structure, and the macroscopic ferroelectric and ferroelastic properties are discussed in detail, allowing a deeper understanding of size effects in polycrystalline donor doped PZT ceramics.
\end{abstract}

Published under license by AIP Publishing. https://doi.org/10.1063/5.0029659

\section{INTRODUCTION}

Despite a significant increase in research on lead-free piezoceramics over the last decade, lead-containing compositions still dominate the market. ${ }^{1}$ Among them, lead zirconate titanate $\left(\mathrm{PbZr}_{\mathrm{x}} \mathrm{Ti}_{1-\mathrm{x}} \mathrm{O}_{3}, \mathrm{PZT}\right)$ based systems are most commonly used in actuator or sensor applications. For this reason, an overwhelming amount of research has been published on the electromechanical properties of PZT across multiple length-scales, revealing considerable details about the strain mechanisms. ${ }^{2-4}$ Therefore, PZT acts as a model system for applied piezoceramics, making it the de facto reference material against which all other systems are compared. The research and commercial interest is due to the huge number of applications for PZT, which is in large part based on the excellent electromechanical properties that can be substantially modified by defect chemistry as well as processed through various methods, including the low-cost mixed oxide route. Importantly, however, the ceramic microstructure, that is, grain size, is influenced both by the doping and by the synthesis procedure, ${ }^{5}$ which have been shown to significantly influence the macroscopic properties such as piezoelectric charge coefficient $\left(\mathrm{d}_{33}\right)$, dielectric permittivity $\left(\varepsilon_{\mathrm{r}}\right)$, and coercive electric field $\left(\mathrm{E}_{\mathrm{C}}\right) \cdot{ }^{6-9}$ For example, early work on barium titanate $\left(\mathrm{BaTiO}_{3}\right)$ showed a maximum permittivity at a grain size of $\approx 1 \mu \mathrm{m},{ }^{10}$ which is still the subject of scientific investigations. ${ }^{6}$ Furthermore, thin films or layers of ferroelectric materials have different properties and phases in contrast to conventionally produced materials. This results, among other factors, from their variation in particle sizes, ${ }^{11}$ which typically ranges from a few hundred nanometers to several micrometers. Thin films show in 
general much smaller grain sizes in contrast to conventionally manufactured polycrystalline bulk materials. ${ }^{11}$

Apart from the microstructure, which describes the grain size, morphology, and their interactions, the domain structure inside the grains also has a significant impact on the dielectric and electromechanical properties. The domain structure in PZT varies depending on stoichiometry ${ }^{12}$ and doping, ${ }^{13}$ as well as the loading history of the sample, that is, the application of external thermal, electrical, and mechanical fields. The formation of ferroelectric domains is a consequence of a phase transformation from a higher symmetry paraelectric phase to a lower symmetry ferroelectric phase. The domain structure represents, therefore, the energy minimization between the elastic, electric, and surface energy on one side and the domain wall energy on the other side. ${ }^{14}$ Different boundary conditions lead to a different twinning from a complex 3D-domain structure to a simple lamellar twinning as shown earlier. ${ }^{7,14-17}$

The orientation of the spontaneous polarization is bound to the local crystal structure. In the PZT system, under the consideration of a rhombohedral and a tetragonal crystal structure, domain configurations of $71^{\circ}, 109^{\circ}$, and $180^{\circ}$ as well as $90^{\circ}$ and $180^{\circ}$ are possible, respectively. Internal mechanical stress fields, however, can be only accommodated by $71^{\circ}$ and $109^{\circ}$ domain walls for the rhombohedral phase and $90^{\circ}$ domain walls for the tetragonal phase. ${ }^{18}$ MacLaren et al. calculated peak stresses of about $1 \mathrm{GPa}$, which are at least partially accommodated by additional defects such as dislocation arrays in the boundaries. However, only non- $180^{\circ}$ domain configurations contribute to a decrease in elastic energy. ${ }^{14,19,20}$ A more detailed consideration with regard to $90^{\circ}$ and $180^{\circ}$ domain walls is shown in Figs. 1 (a) and $1(\mathrm{~b})$. With $90^{\circ}$ domain walls, a change of the crystal orientation causes a strong mechanical stress field [Fig. 1(a)]. ${ }^{18,21,22}$

Fundamental investigations of the influence of grain size on the properties of donor-doped PZT ceramics have already been carried out by various research groups. ${ }^{7,15,25}$ A systematic investigation of the grain size influence in connection with a variation of the defect chemistry and its effect on the electromechanical properties of PZT ceramics with grain sizes down to the sub-micrometer range, however, is not available. Therefore, in this work, we comprehensively discuss the effect of grain size in donor doped PZT ceramics.

\section{EXPERIMENTAL METHODOLOGY \\ A. Preparation of the ceramics}

PZT samples were prepared from high purity $\mathrm{PbO}$ (Alfa Aesar, $>99.99 \%$ ) and a zirconium titanium hydrate precursor $(\mathrm{ZTH})$. To obtain the equivalent molar ratio of $\mathrm{Zr} / \mathrm{Ti}=0.52 / 0.48$, a mixture of two different $\mathrm{ZTH}$ with $\mathrm{Zr} / \mathrm{Ti}=57.6 / 42.4$ and 44.8/55.2 were used (Crenox $\mathrm{GmbH}$, >99.99\%). Anatase titanium dioxide hydrate particles with a BET specific surface area of $380 \mathrm{~m}^{2} / \mathrm{g}$ were produced by hydrolyzing a titanyl sulfate solution. In a second step, the zirconia component was precipitated on the surface of the titanium dioxide nanoparticles by using a $\mathrm{Zr}$-containing solution and subsequent neutralization by adding sodium hydroxide. The mixture was then filtrated, washed, and dried. Details regarding the synthesis method can be found elsewhere. ${ }^{26-28}$ The resulting BET specific surface area of the ZTH was $310 \mathrm{~m}^{2} / \mathrm{g}$, which gives a $d_{50}$, BET of $4 \mathrm{~nm}$ by using the equation $d_{50, B E T}=6 / \rho \cdot S_{B E T}$, where $\rho$ is the density of the material and $S_{B E T}$ is the specific surface area of the powder. $S_{B E T}$ was measured using a Flow Sorb II 2300 (Micromeritics). The ignition loss of the ZTH was measured after a heat treatment at $1100^{\circ} \mathrm{C}$ for $4 \mathrm{~h} . \mathrm{La}_{2} \mathrm{O}_{3}$ was dried at $600^{\circ} \mathrm{C}$ for $2 \mathrm{~h}$. Due to the complex sintering behavior of $\mathrm{ZTH}$, a PbO excess of $2 \mathrm{~mol} \%$ was used. The chemical composition used was $P b_{1.005} L a_{0.01} V_{P b_{0.005}}^{\prime \prime}\left(Z r_{0.52} T_{0.48}\right) O_{3}$.

$\mathrm{PbO}, \mathrm{ZTH}$, and $\mathrm{La}_{2} \mathrm{O}_{3}$ were mixed and attrition-milled for $3 \mathrm{~h}$ at $1000 \mathrm{rpm}$ in isopropanol using Y-TZP milling balls ( $2 \mathrm{~mm}$ diameter), according to the above-mentioned stoichiometry by including the ignition loss of the ZTH. After drying the slurry in a rotating evaporator, the powder mixture was sieved in a $160 \mu \mathrm{m}$ mesh metal (a)

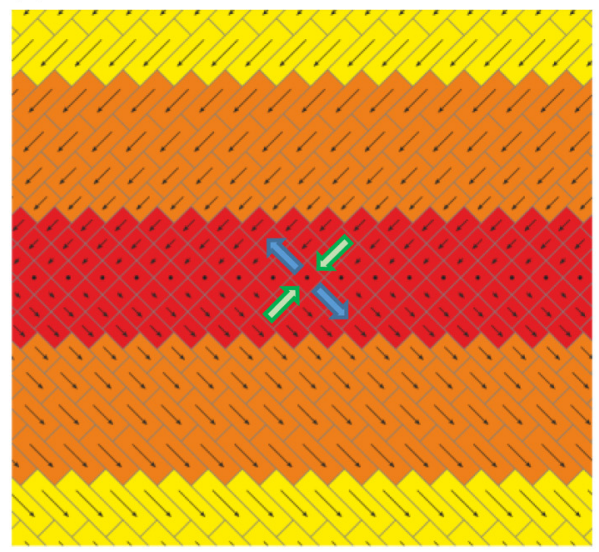

(b)
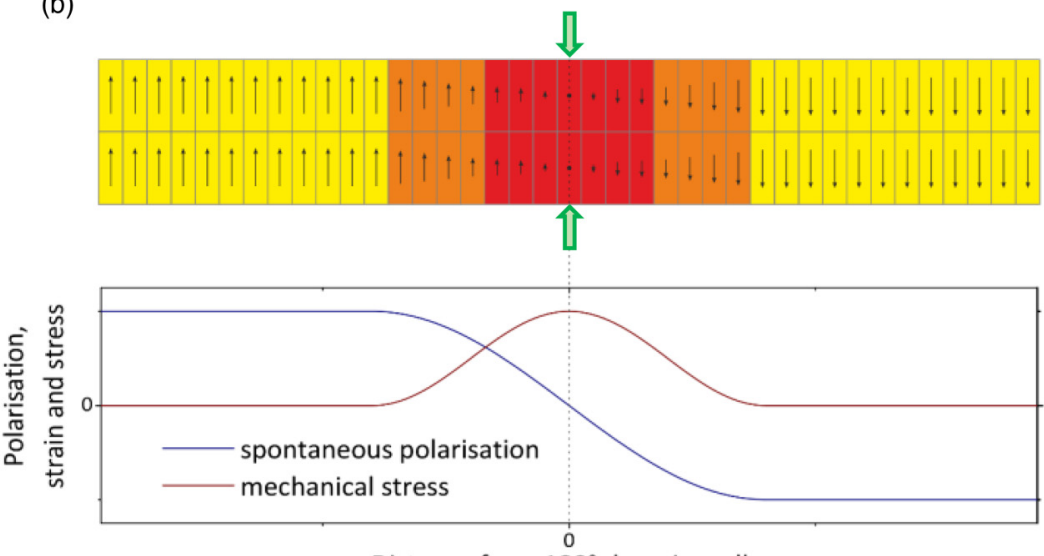

Distance from $180^{\circ}$ domain wall $\mathrm{x}$

FIG. 1. (a) Schematic representation of a $90^{\circ}$ domain wall. (b) Simple $180^{\circ}$ domain configuration showing the change in mechanical stress and spontaneous polarization across the domain wall. ${ }^{23}$ Black arrows indicate the spontaneous polarization magnitude in the unit cells. Blue and green arrows mark the existing tensile (blue) and compressive (green) stresses, respectively.22,24 
sieve. Calcination was performed at $600^{\circ} \mathrm{C}$ for $2 \mathrm{~h}$ in alumina crucibles. The calcinated powder had a BET specific surface area of $6.3 \mathrm{~m}^{2} / \mathrm{g}$, corresponding to a $\mathrm{d}_{50, \mathrm{BET}}$ of $120 \mathrm{~nm}$. Without a further milling step, the powder was formed into cylinders of $12 \mathrm{~mm}$ diameter by uniaxial pressing and subsequent cold isostatic pressing at $400 \mathrm{MPa}$. The samples were sintered in a closed alumina crucible at sintering temperatures $\mathrm{T}_{\mathrm{S}}=875-1250^{\circ} \mathrm{C}$ for $2 \mathrm{~h}$. For temperatures above $1100{ }^{\circ} \mathrm{C}$, a powder bed out of $\mathrm{PbZrO}_{3} / \mathrm{ZrO}_{2}$ was used. ${ }^{29}$ The grain size was calculated after a statistical analysis of 300-500 grains (AnalySIS, Soft Imaging).

\section{B. Piezoresponse force microscopy}

The local domain structure was investigated by piezoresponse force microscopy (PFM) with an AFM Dimension 3000 (Veeco Instruments) and by using a $\mathrm{Pt} / \mathrm{Ir}$ conductive tip (Nanosensors) at $\omega=10 \mathrm{kHz}$ and $\mathrm{V}_{\mathrm{ac}}=20 \quad \mathrm{~V}_{\mathrm{PP}}$ applied to the tip. PFM signals were demodulated with two lock-in amplifiers (Signal Recovery 7225 and 7265, AMETEK). The samples were polished with an additional polishing step by using an alkali suspension (Mastermet, Struers $\mathrm{GmbH}$ ). After the ceramographic preparation, the samples were annealed at $500{ }^{\circ} \mathrm{C}$ for $4 \mathrm{~h}$ to remove the crystallographic texture induced by mechanical stresses during polishing.

\section{In situ electric-Field-Dependent synchrotron x-ray diffraction}

Synchrotron $\mathrm{X}$-ray experiments were performed at beamline P02.1 at PETRA III of the Deutsches Elektronensynchrotron (DESY) in Hamburg, Germany. ${ }^{30,31}$ The wavelength was $\lambda=0.207015 \AA$, and data were collected with a Perkin Elmer 2D detector with a sample-to-detector distance optimized for high angular resolution. ${ }^{30}$ The bar-shaped samples with dimensions of approximately $1 \times 1 \times 5 \mathrm{~mm}^{3}$ were prepared with platinum electrodes on polished opposing long sides. The electric field for in situ experiments was applied with a TREK 10/40A-HS-H-CE in a specially developed sample environment. ${ }^{32,33}$

Data analysis was performed with the software package MAUD. ${ }^{34}$ Due to significant anisotropic reflection broadening, a structure model consisting of a tetragonal $P 4 \mathrm{~mm}$ and a monoclinic model $\mathrm{Cm}$ phase was used for the refinement. For poled samples, additional strain and texture parameters were used with a structure model consisting of a tetragonal $P 4 \mathrm{~mm}$ and a rhombohedral $R 3 \mathrm{~m}$ phase. Detailed information can be found elsewhere. ${ }^{2,3,13}$

\section{Electromechanical and dielectric measurements}

High field strain and polarization were measured using a piezoanalyzer (aixACCT TF Analyzer 2000) equipped with a laser interferometer for strain measurements, a high voltage source, and a virtual ground device for the polarization measurement. The disk-shaped samples had a thickness of $1 \mathrm{~mm}$ and a diameter of $10 \mathrm{~mm}$. Silver electrodes were prepared by firing a silver paste (Gwent C2060217D3) on the ceramic disks at $600{ }^{\circ} \mathrm{C}$. The samples were then subsequently poled at room temperature at $5 \mathrm{kV} / \mathrm{mm}$. The unipolar large field polarization and strain were measured at $2 \mathrm{kV} / \mathrm{mm}$ using a triangular waveform with a frequency of $25 \mathrm{mHz}$. The large field piezoelectric coefficient was then calculated by $d_{33}^{*}=S_{\max } / E_{\max }$. Similar samples were used to analyze the dielectric permittivity of the poled $\left(\varepsilon_{p o l}^{\prime}\right)$ and unpoled $\left(\varepsilon_{\text {unpol }}^{\prime}\right)$ samples between 20 and $10^{6} \mathrm{~Hz}$ by using a LCR-Meter 4284A (Hewlett Packard).

\section{E. Ferroelastic measurements}

Ferroelastic measurements were conducted with a screw-type load frame (Z030, Zwick GmbH \& Co.KG). The applied load was controlled by a load cell and the displacement was measured with a custom-built linear variable differential transformer system. ${ }^{35}$ Cylindrical samples with a height of $6.00 \mathrm{~mm}( \pm 0.01 \mathrm{~mm})$ and a diameter of $5.80 \mathrm{~mm}( \pm 0.01 \mathrm{~mm})$ were loaded from an initial preload of $-5 \mathrm{MPa}$ to a maximum load of $-500 \mathrm{MPa}$ and unloaded to preload. The loading rate of $5 \mathrm{MPa} / \mathrm{s}$ was used during the measurements.

\section{RESULTS AND DISCUSSION}

\section{A. Part I: Domain and crystal structure in the unpoled state}

\section{Domain structure (PFM)}

Figure 2 shows an overview of the PFM analysis of samples with different grain sizes, where Figs. 2(a)-2(e) illustrate the PFM in-plane signal and Figs. 2(b)-2(f) show the corresponding simplified domain configurations in the highlighted grains. The average grain sizes of the ceramics are $4.67 \mu \mathrm{m}, 1.40 \mu \mathrm{m}$, and $0.55 \mu \mathrm{m}$. The

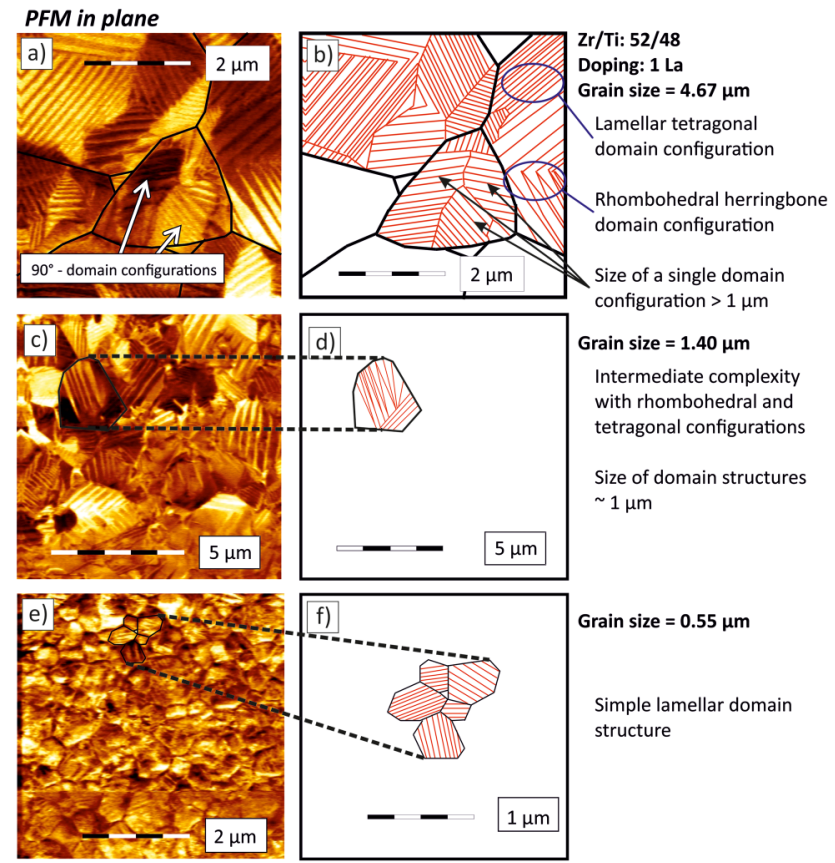

FIG. 2. PFM analysis of the in-plane signal of samples with different grain sizes. (a) $4.67 \mu \mathrm{m}$, (c) $1.40 \mu \mathrm{m}$, and (e) $0.55 \mu \mathrm{m}$. (b), (d), and (f) show the corresponding simplified domain configuration in the marked grains. 
sample with an average grain size of $4.67 \mu \mathrm{m}$ [Figs. 2(a) and 2(b)] shows a complex twinned domain structure with several configurations within one grain. It is also apparent that some grains display domain structures consistent with both rhombohedral and tetragonal phases. Smaller grains of about $2 \mu \mathrm{m}$ show several $90^{\circ}$ domain configurations within one grain. The diameter of most uniform domain configurations is larger than $1 \mu \mathrm{m}$ [Fig. 2(a)]. The sample with a grain size of $1.40 \mu \mathrm{m}$ [Figs. 2(c) and 2(d)] still shows a complex domain structure within the grains; however, most grains show a single type of domain configuration or the coexistence of two different domain configurations. The diameter of these uniform domain configurations is around $1 \mu \mathrm{m}$ in most grains [Fig. 2(c)]. By further decreasing the grain size to $0.55 \mu \mathrm{m}$ [Figs. 2(e) and 2(f)], the domain configuration is found to change into a simple lamellar and mostly $90^{\circ}$ domain structure. The complexity of the domain structures reaches a minimum and the size of the domain structures is in the range of the grain size.

As already described, the formation of ferroelectric domains and their configuration is due to the equilibrium between the energy penalty for the formation of a domain wall, the electrical depolarization energy, and the mechanical stress field. ${ }^{14,36}$ The polarization energy results from the depolarizing electric field inside a ferroelectric that is proportional to the polarization and can be described by $E_{\text {depol }}=-L \cdot P / \varepsilon_{0}$, where $L$ is the depolarization vector. ${ }^{36}$ Theoretical calculations suggest that the domain size $d$ is proportional to the square root of the ceramic grain size $g$, $d \propto \sqrt{g} .^{37,38}$ This has also been demonstrated in PZT ceramics in the compositions around the morphotropic phase boundary (MPB). ${ }^{7,25,39,40}$ Figure 3 shows the observed domain sizes as a function of the grain size for a range of doped PZT systems; the corresponding fit shows good agreement with other literature data. It is apparent from this dependence between domain size and grain size that the increase in the domain wall density $\rho_{D}$ within the material

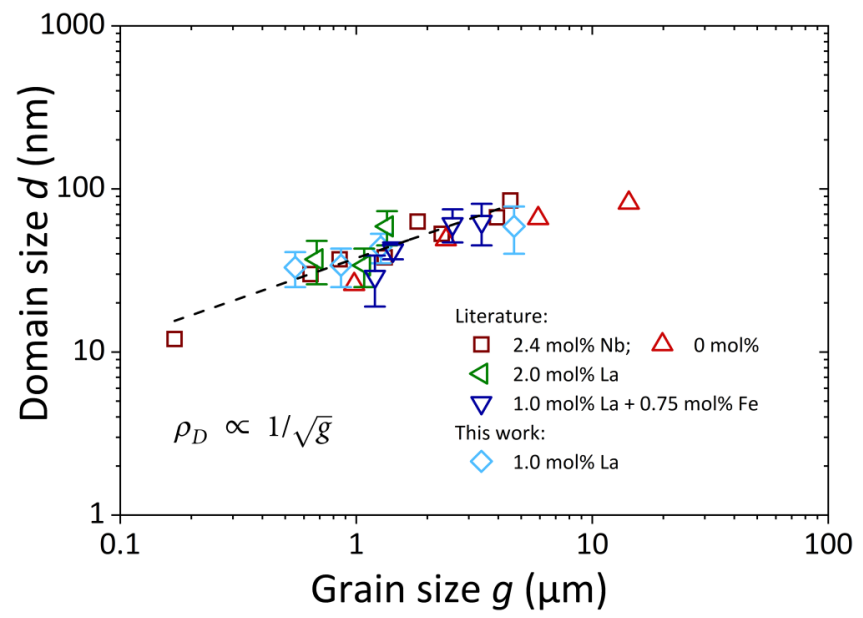

FIG. 3. Domain size as a function of the grain size for different PZT ceramics. Literature data: $\left(0,2.4 \mathrm{~mol} . \% \quad \mathrm{Nb},{ }^{7} \quad 1.0,2.0 \mathrm{~mol} . \% \mathrm{La}\right.$ and $1 \mathrm{~mol} . \%$ $\mathrm{La}+0.75 \mathrm{~mol} . \% \mathrm{Fe}^{38}$ this work). follows the relation $\rho_{D} \propto 1 / \sqrt{g} .^{20}$ Material parameters such as unit cell distortion depend on the composition of the solid solution and are an intrinsic property. Even poled materials, with significant domain reorientation and reconfiguration of stress states, exhibit the same unit cell distortion in the remanent state as in the unpoled state. ${ }^{3}$ The unit cell distortion, on the other hand, has a fundamental correlation with the stress states at the domain wall. ${ }^{18}$ Even though the thickness of domain walls is still a matter of debate, the stress amplitude at a domain wall and its thickness are correlated. When the domain wall density increases, the volume fraction of the material, affected by the structural distortions near a domain wall, increases for decreasing grain sizes.

\section{Crystal structure (bulk, synchrotron $x$-ray diffraction)}

Figure 4(a) depicts the $\mathrm{x}$-ray diffraction patterns of all investigated grain sizes; subscripts $\mathrm{C}, \mathrm{T}$, and $\mathrm{R}$ denote pseudocubic, tetragonal, and rhombohedral indexing, respectively. With a decreasing grain size, the $111_{\mathrm{C}}$ reflection shows a continuous peak broadening, whereas the $200_{\mathrm{C}}$ reflection demonstrates a clear structural trend toward the non-tetragonal symmetry. While the sample with the largest grain size shows a pronounced tetragonal splitting of the $200_{C}$ reflection, with decreasing grain size, the reflections exhibit a continuously increasing asymmetric broadening down to about $1 \mu \mathrm{m}$ as well as a decrease in reflection splitting. Particularly, the low angle $002_{\mathrm{T}}$ reflection is shifted to higher angles, indicating a decrease in unit cell distortion. For the samples with grain sizes below $1 \mu \mathrm{m}$, an additional intensity can be observed, and below $0.5 \mu \mathrm{m}$, a clearly visible additional reflection appears, which can be attributed to a non-tetragonal phase or domain wall effects. ${ }^{13}$ More details can be found in Fig. S1 of the supplementary material.

Using Rietveld refinement, the unit cell distortion $\eta_{T}$ was determined,

$$
\eta_{T}=\frac{c_{T}}{a_{T}}-1
$$

with $c_{T}$ and $a_{T}$ being the lattice parameters of the tetragonal unit cell. More details about the refinement can be found in the supplementary material. Figure 4(b) shows the change in unit cell distortion as a function of grain size for the coexisting tetragonal and non-tetragonal phases. The initial unit cell distortion at a grain size of $4.67 \mu \mathrm{m}$ is approximately $2.45 \%$ for the tetragonal and $1.50 \%$ for the nontetragonal phase. Interestingly, both unit cell distortions continuously decrease with decreasing grain size in the unpoled state, where the non-tetragonal phase shows a substantial decrease below around $1 \mu \mathrm{m}$ and the tetragonal phase below around $0.5 \mu \mathrm{m}$, corresponding to the observation of the additional reflection in Fig. 4(a) (black arrow). This decrease in unit cell distortion reflects the increase in the influence of the domain wall density on the structure. Since diffraction results in an average information about the crystal structure, the increased volume fraction of the distorted structure in the vicinity of domain walls is reflected by the decrease in unit cell distortion. This corresponds well to previous work, where the influence of domain walls was suggested to have an impact on the diffraction patterns. ${ }^{13}$

Diffraction data reveal that the decrease in the unit cell distortion is also accompanied by a decrease in the unit cell volume for 
(a)

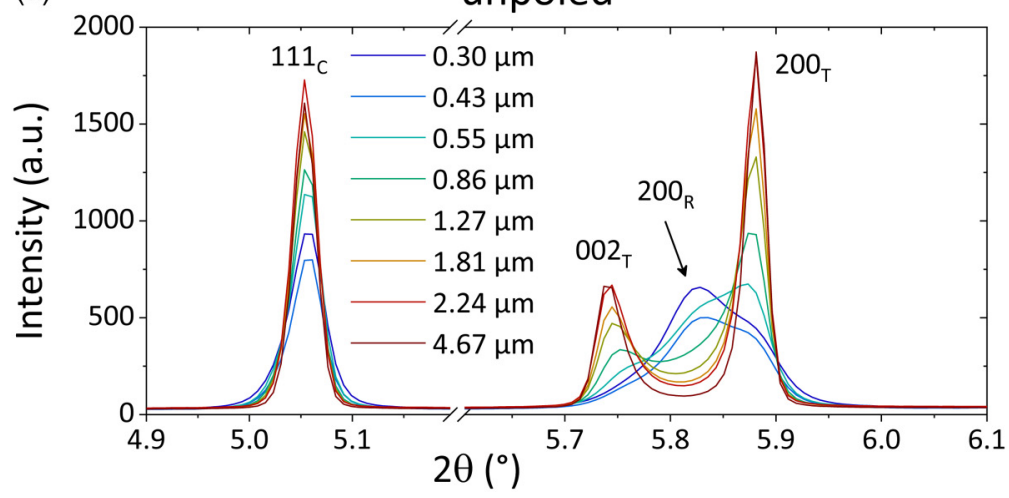

(b)

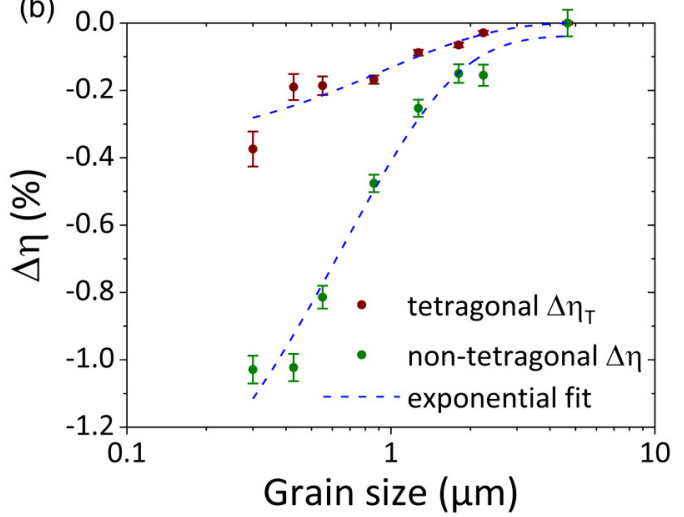

FIG. 4. (a) X-ray diffraction patterns of the $111_{C}$ and $200_{C}$ reflections for all investigated grain sizes. The black arrow indicates additional reflection. (b) Change in unit cell distortions $\eta$ as a function of the grain size for the two observed crystallographic phases.

the tetragonal phase, whereas the non-tetragonal phase shows no change within the error range. Importantly, due to significant reflection broadening in the non-tetragonal phase, the error bars are significantly larger than in the tetragonal phase. Figure 5(a) shows the characteristic relative unit cell volume. It is suggested that the unit cell volume reduction is largely due to increasing internal stress fields with decreasing grain size. Since the bulk modulus of PZT was previously determined, ${ }^{41}$ the resulting quasihydrostatic pressure can be calculated using the simplified BirchMurnaghan equation of state, ${ }^{42}$

$$
p(V)=\frac{3 B_{0}}{2}\left[\left(\frac{V_{0}}{V}\right)^{\frac{7}{3}}-\left(\frac{V_{0}}{V}\right)^{\frac{5}{3}}\right],
$$

(a)

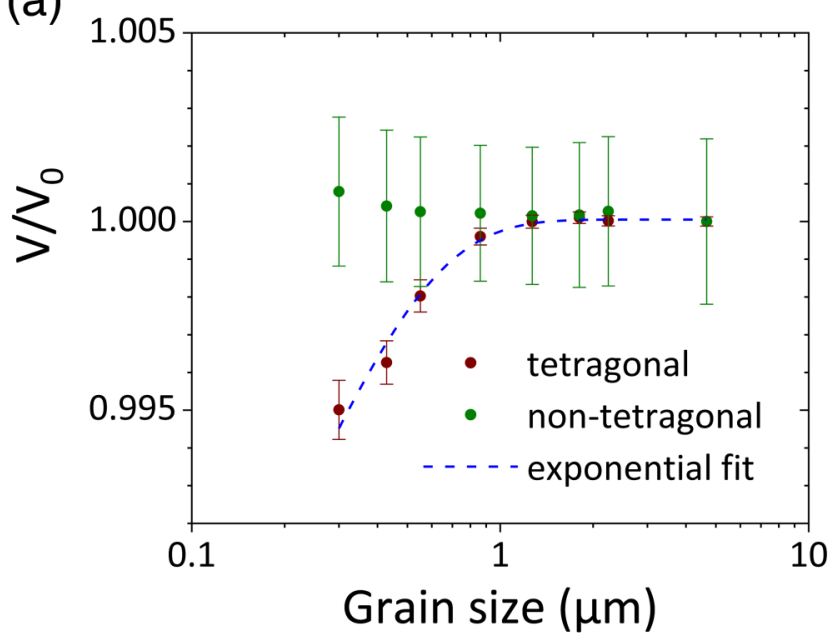

with $V_{0}=67.31 \AA^{3}$ for a grain size of $4.67 \mu \mathrm{m}$ and $B_{0}=92 \mathrm{GPa}$ for pressures up to around $5 \mathrm{GPa} .{ }^{41}$ The quasihydrostatic pressure, recalculated from the relative change of the unit cell volume, increases dramatically for grain sizes below $1 \mu \mathrm{m}$ [Fig. 5(b)]. Since the unit cell volumes are calculated from the unit cell parameters determined from diffraction, they represent an average value over the whole illuminated bulk volume. Therefore, the actual values at the domain walls will be higher. Previous transmission electron diffraction experiments lead to estimates of around $1 \mathrm{GPa}$ for a unit cell distortion of around $2.5 \%{ }^{18}$ Here, the average bulk volume behaves as under a hydrostatic pressure of up to $250 \mathrm{MPa}$ for the smallest grain sizes, which is in the range of the blocking force for PZT materials at the MPB. ${ }^{43}$ The increasing effect of the mechanical stresses on the domain and crystal structure as well as the spontaneous polarization is schematically illustrated in Fig. 6.

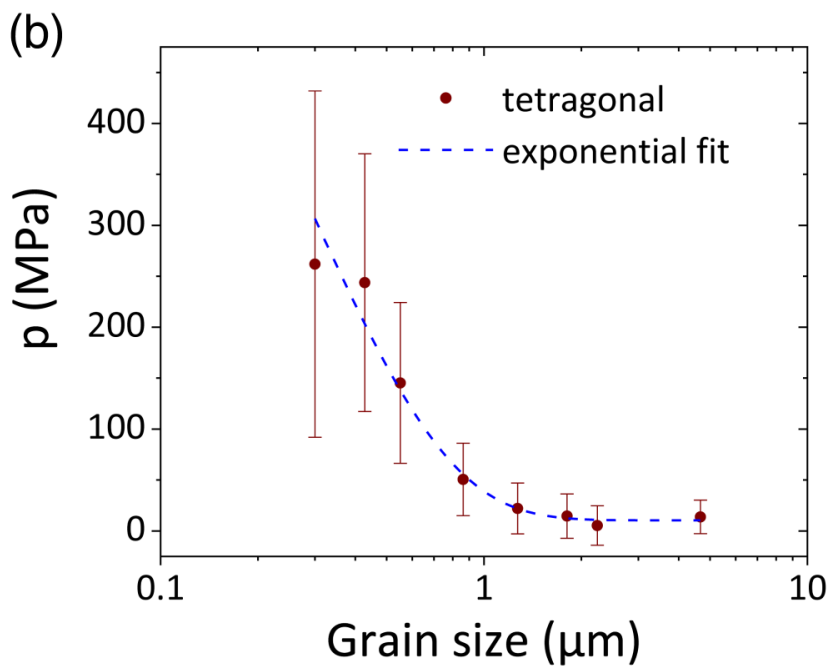

FIG. 5. (a) Relative unit cell volume. (b) Recalculated quasihydrostatic pressure. 

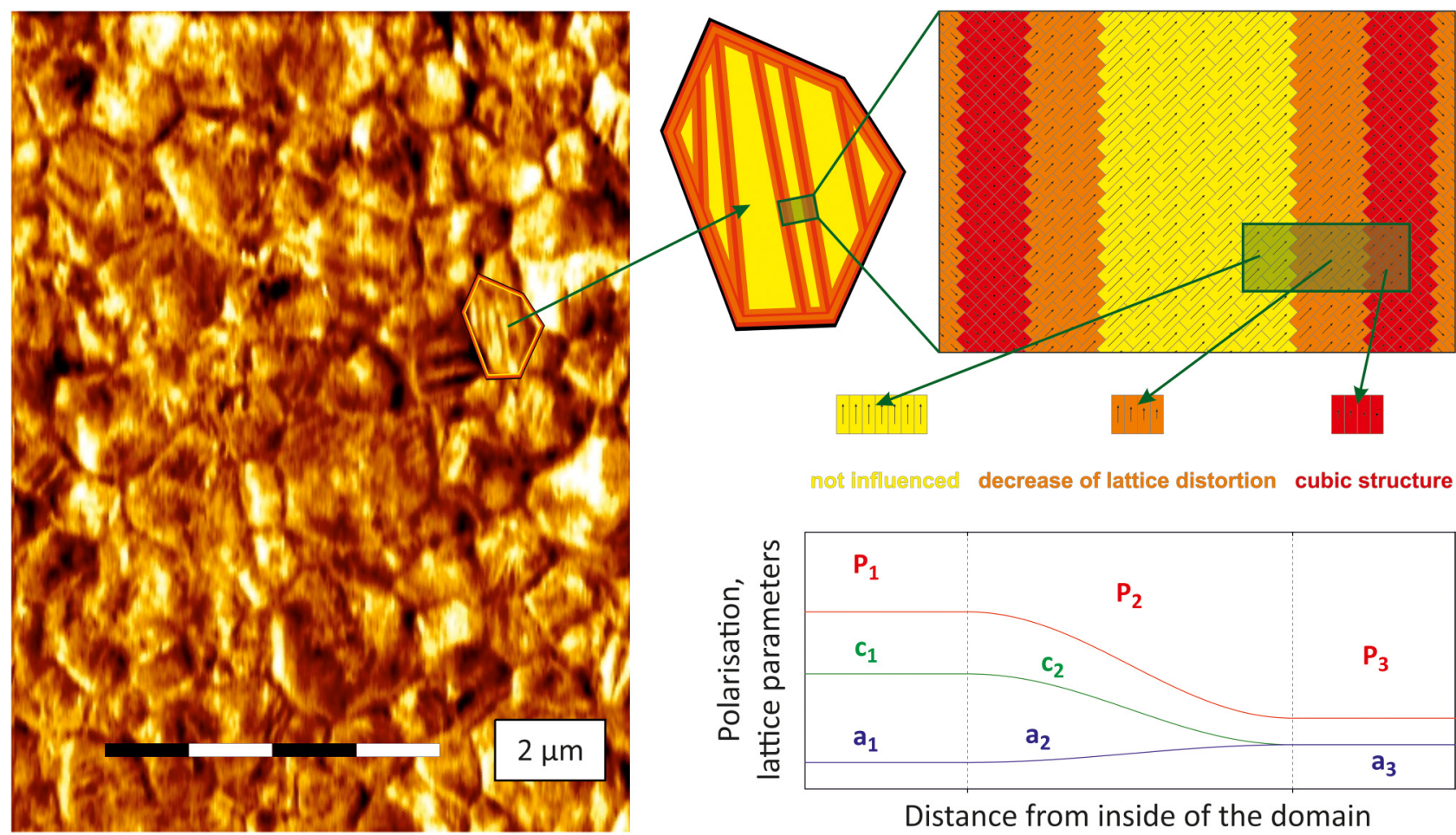

not Inflluenced decrease of lattice distortion cubic structure

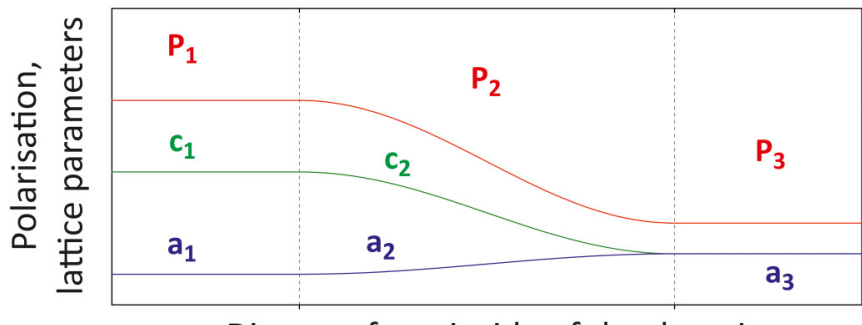

Distance from inside of the domain

FIG. 6. Schematic representation of a microstructure for grain sizes below $1 \mu \mathrm{m}$ and the observed domain configuration with the influence on the crystal structure and electromechanical properties. The size of the black arrows indicates the spontaneous polarization magnitude in the unit cells.

\section{B. Part II: Domain and crystal structure in the poled state}

\section{Electric field-dependent crystal structure}

The application of an electric field significantly changes the observed diffraction patterns of PZT, which can be seen in Fig. 7(a) for an applied field of $5 \mathrm{kV} / \mathrm{mm}$ for all investigated grain sizes. The sample orientation, $\psi=45^{\circ}$, was chosen in order to investigate the effects of the field-induced phase transformation. ${ }^{44,45}$ Interestingly, the grain size influences the material response to the applied electric field. The largest investigated grain size shows only an intensity shift between the $200_{\mathrm{C}}$ reflections compared to the unpoled state in (a)

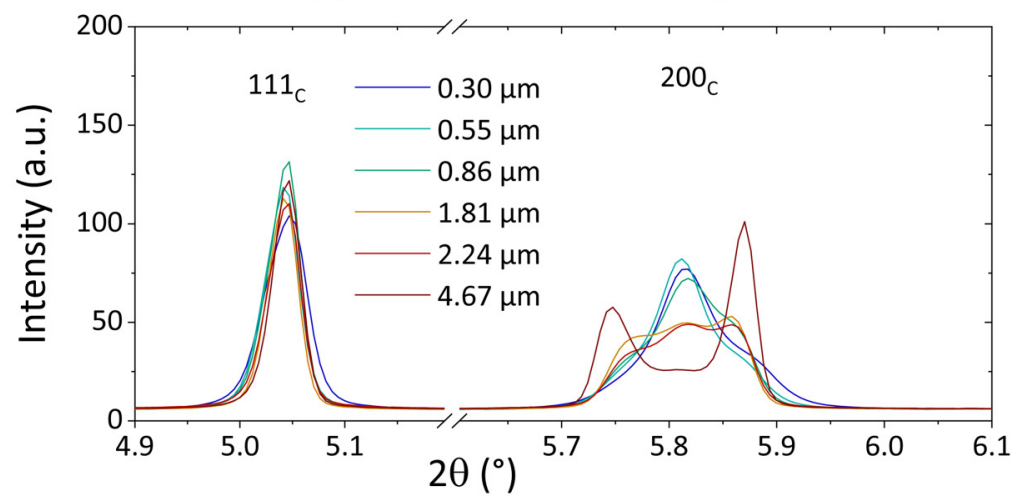

(b)

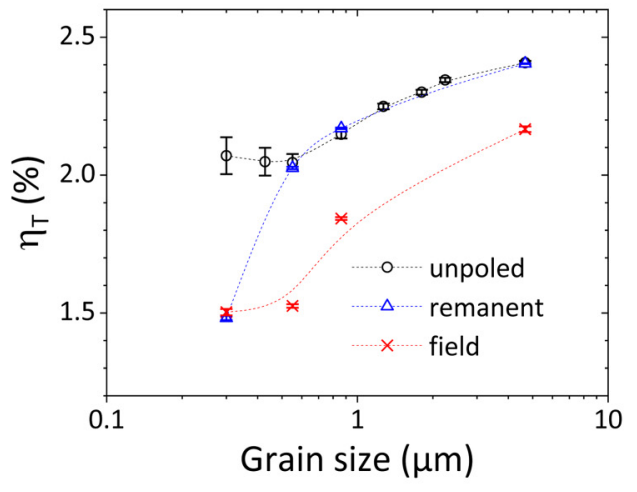

FIG. 7. (a) X-ray diffraction patterns of the $111_{\mathrm{C}}$ and $200_{\mathrm{C}}$ reflections under an applied electric field of $5 \mathrm{kV} / \mathrm{mm}$ and (b) tetragonal unit cell distortion $\eta_{\mathrm{T}}$ of the unpoled, remanent, and applied field state for all investigated grain sizes. Lines are guides for the eyes. 
Fig. 4(a), whereas all other grain sizes show a significant increase in the reflection intensity of the non-tetragonal reflection as well as a corresponding decrease in unit cell distortion.

In order to quantitatively investigate the structural changes, the structure was analyzed with a texture refinement of all investigated sample orientations. ${ }^{2,3}$ Figure 7 (b) shows the resulting tetragonal unit cell distortion of these refinements, revealing several trends. As described before, for grain sizes above $1 \mu \mathrm{m}$, the unit cell distortion of the unpoled and remanent state is the same and decreases slightly toward smaller grain sizes. For grain sizes above $0.5 \mu \mathrm{m}$, the unit cell distortion was found to initially decrease during the application of an electric field, but then subsequently return to the original value of the unpoled state following removing of the applied electric field. This contradicts the classical model of the inverse piezoelectric effect, which predicts an increase of unit cell distortion with the applied field. However, this is again an effect of the averaging from the diffraction experiment. ${ }^{3}$ The domains have a unit cell distortion of around $2.0 \%$ to $2.4 \%$. A full $90^{\circ}$ domain switching along the field would result in a similar expansion of the respective grain. Due to intergranular stresses, the resulting unit cell distortion of the switched domains is smaller than the initial one. Therefore, the average unit cell distortion decreases with increasing field, since more domains are switched. In the remanent state, the unit cell distortion is determined by the material composition and is identical to the unpoled state. More information about the unit cell parameters can be found in Fig. S2 of the supplementary material.

The difference between the unit cell distortion of the unpoled and applied field state is similar down to about $1 \mu \mathrm{m}$. For smaller grain sizes, the difference increases significantly due to the strong influence of the domain walls. This is a direct indication of the quasihydrostatic pressure shown in Fig. 5(b). Between $1 \mu \mathrm{m}$ and $0.5 \mu \mathrm{m}$, this value increases from below $50 \mathrm{MPa}$ to $150 \mathrm{MPa}$. At this high level of stress, the domain walls can still move reversibly, although the resulting unit cell distortion is significantly decreased under the applied field. For grain sizes below $0.5 \mu \mathrm{m}$, however, the switching occurs irreversibly, which results in a significantly reduced unit cell distortion due to the same reasons as discussed before. However, the redistributed stresses are too large for a reversible switching of the domain configuration. This means that for small grain sizes, the unit cell distortion decreases upon first poling and irreversibly remains in the poled state. The difference in unit cell distortion between applied field and remanent state is smallest at a grain size of $0.30 \mu \mathrm{m}$.

For large grains, the applied electric field results in a redistribution of stresses due to the realigned domain structures. Since the remanent and unpoled states have identical unit cell distortions, this indicates that the unit cell distortion is mainly determined by the intrinsic properties of the material. The complex domain configurations in one single grain allow a redistribution of stresses and an equilibrium develops between inter- and intragranular stresses. For small grains, the simple domain structure can only lead to an anisotropic deformation and distribution of stresses. Down to a certain grain size, a reversible switching remains possible, although with large differences in unit cell distortions. When the grain size reaches a critical minimum size, the effects of the field-induced processes are too large and result in an irreversible change in domain configurations and unit cell distortion.

\section{Electromechanical behavior}

As can be seen from Fig. 8, a reduction of the grain size significantly influences the large field strain and polarization hysteresis behavior. The coarse-grained samples exhibit a behavior well known from the literature, marked by an increased remanent strain and a reduction in coercive field. In contrast, a reduction in grain (a)

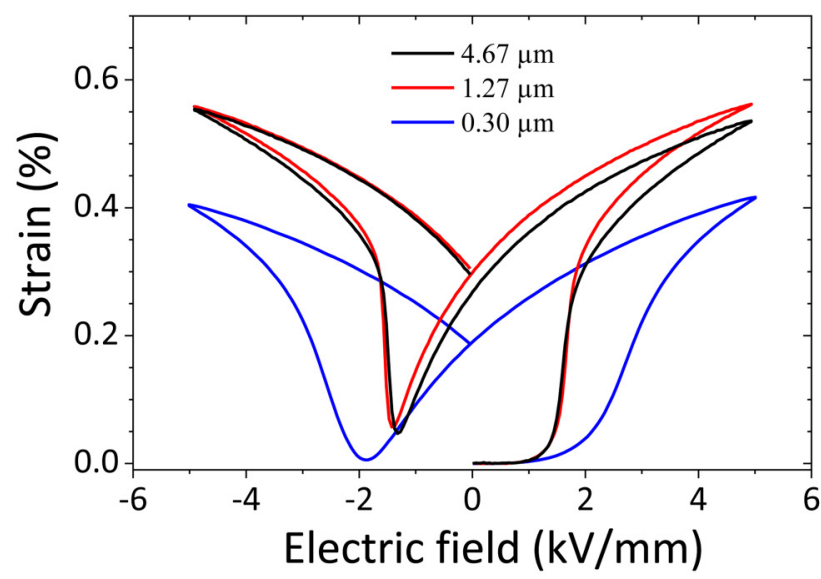

(b)

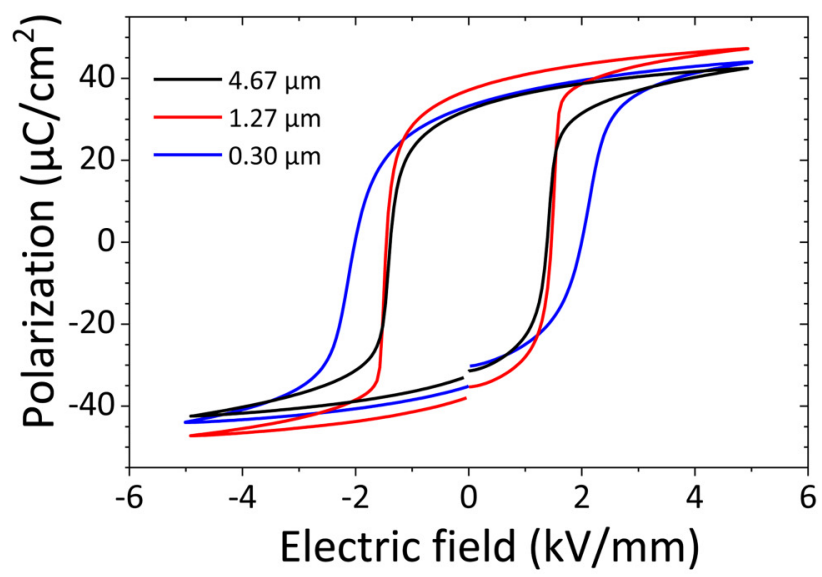

FIG. 8. (a) Strain hysteresis loops and (b) polarization hysteresis loops for different grain sizes. With a decrease of the grain size from $4.67 \mu \mathrm{m}$ to $1.27 \mu \mathrm{m}$, a slight increase in the remanent strain $S_{\text {rem }}$ can be seen, while for a grain size of $0.30 \mu \mathrm{m}$, a significant reduction results (a). A detailed representation of the grain size influence on $S_{\text {rem }}$ is shown in Fig. $9($ d). 
size increases the coercive field [Fig. 9(a)], which was also observed by other authors. ${ }^{8,25,46-48}$ This as well reduces the remanent strain.

The remanent strain is related to the distortion of the perovskite lattice and the angle $\theta$, which represents the deviation between the polarization axis of a domain and the poling field. The maximum remanent strain for tetragonal materials, thus, can be expressed as ${ }^{49}$

$$
S_{r e m, T}=\left(\left\langle\cos ^{2} \theta\right\rangle-\frac{1}{3}\right) \eta_{T}
$$

For a reduction of the grain size, an increase in $S_{\text {rem }}$ can be observed down to $\approx 0.6 \mu \mathrm{m}$. The trend of $S_{\text {rem }}$ observed in Fig. 9(d) for grain sizes between 5 and $1 \mu \mathrm{m}$ shows a very good agreement with conventionally prepared $\mathrm{PZT}$ with identical effective donor content. ${ }^{47}$ For grain sizes below $\approx 0.6 \mu \mathrm{m}$, a strong decrease in $S_{\text {rem }}$ is observed. Considering only a minor change in the crystal structure, it can be concluded that an increased contribution to non- $180^{\circ}$ domain switching processes leads to an increase in $S_{r e m}$ that is observed between 5 and $1 \mu \mathrm{m}$. This is in agreement with the observed change in the domain configuration from a complex 3D domain structure to a simple lamellar arrangement. Samples with a grain size $<1 \mu \mathrm{m}$ show only a simple $90^{\circ}$ domain configuration. If the grain size is further reduced, there is a marked decrease in the unit cell distortions $\eta_{T}$ and $\eta_{R}$, which possibly leads to a sharp decrease in $S_{\text {rem }}$ below $\approx 0.6 \mu \mathrm{m}$.

Another measure of the domain switching occurring during electrical poling is the remanent polarization $P_{\text {rem }}$, shown in Fig. 9 (c) as a function of the grain size. Fesenko and Dantsiger ${ }^{50-52}$ have carried out detailed work on the description of $P_{\text {rem }}$, which can be described for the tetragonal phase by the following expression: ${ }^{49,50}$

$$
P_{r e m, T} \cong 6\left(\frac{1}{3}+\frac{2}{3} \delta\right) \sqrt{\eta_{T}} C / m^{2},
$$

where $\delta$ is the mobility of non- $180^{\circ}$ domain wall switching processes during poling (extrinsic contribution)..$^{53}$

The distortion of the perovskite lattice and the number of non- $180^{\circ}$ domain switching processes, thus, largely determine the remanent polarization. From Fig. 9(c), it can be seen that with a reduction of the grain sizes from $1 \mu \mathrm{m}$ to about $\approx 0.6 \mu \mathrm{m}$, $P_{\text {rem, } T}$ increases. In the range between $5 \mu \mathrm{m}$ down to $1 \mu \mathrm{m}$ [Figs. 4(b) and 7(b)], the unit cell distortion only slightly decreases. Since the unit cell distortion starts to decrease for grain sizes below $1 \mu \mathrm{m}$, this increase occurs due to an increased number of non- $180^{\circ}$ domain switching processes.

Even though $P_{\text {rem }}$ depends on both $180^{\circ}$ and non- $180^{\circ}$ domain switching processes, in contrast to $S_{r e m}$ that only depends on non- $180^{\circ}$ domain switching, the increase of $P_{\text {rem }}$ is analogous to the increase of $S_{\text {rem }}$ with decreasing grain size, correlating with the change in domain structure from a complex $3 \mathrm{D}$ domain configuration to a single-lamellar structure (Fig. 2), as described earlier. With this change in domain arrangement, the proportion of non- $180^{\circ}$ domain walls increases and results in the increase in $P_{r e m}$. For grain sizes below $\approx 0.6 \mu \mathrm{m}$, a reduction of the domain mobility and the substantial reduction of the unit cell distortion lead to a decrease of $P_{\text {rem }}$, emphasized by the significant increase of $E_{\mathrm{c}}$.

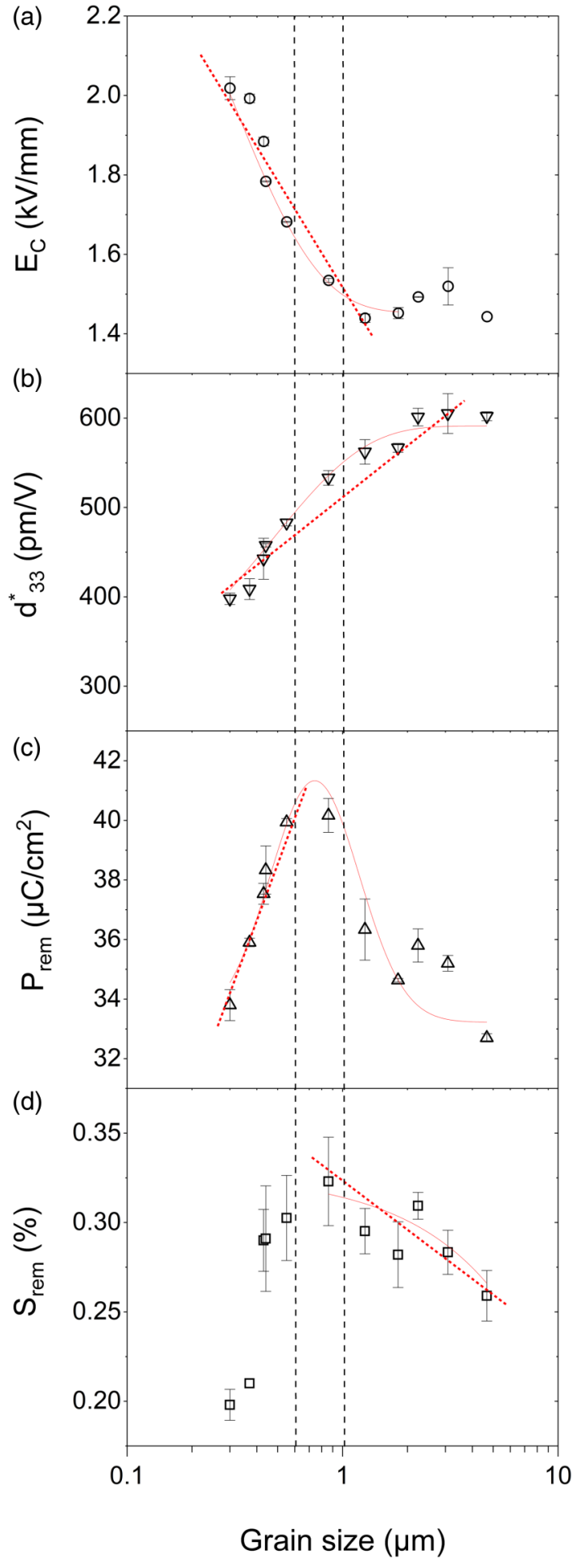

FIG. 9. Influence of the grain size on (a) the coercive field $E_{c}$, (b) the large field piezoelectric coefficient $d_{33}{ }^{*}$ as well as (c) the remanent polarization $P_{\text {rem }}$, and (d) remanent strain $\mathrm{S}_{\text {rem }}$. 
The grain size dependence of the unipolar large field strain is shown in Fig. 9(b). It is apparent that the field-induced strain has an inverse correlation with the grain size dependence of $P_{\text {rem }}$ and $S_{\text {rem }}$, in good agreement with previous results. ${ }^{8,15,47}$ The increased poling strain results in a higher degree of remanent polarization, which leads to a decreasing amount of switchable domains along with a reduction of the grain sizes from $5 \mu \mathrm{m}$ to $1 \mu \mathrm{m}$. At a critical grain size of $1 \mu \mathrm{m}$ and below, a significant decrease in unipolar strain is observed, due to a reduction of orientational variants and the coupling of the domain walls to the grain boundaries. ${ }^{15}$ Thus, both the intrinsic and extrinsic contributions to the large field strain decrease significantly with a further decrease of the grain size. This is also marked by the drastic increase in the coercive field shown in Fig. 9(a).

Figure 10(a) shows the frequency dispersion of the real $\varepsilon^{\prime}$ and imaginary $\varepsilon^{\prime \prime}$ part of the dielectric permittivity in the unpoled state for two different grain sizes in the frequency range between $20 \mathrm{~Hz}$ and $1 \mathrm{MHz}$. The corresponding domain structure is shown in Fig. 10(b). The frequency dispersion follows a logarithmic decrease, which can be described by the following equation: ${ }^{54}$

$$
\varepsilon^{\prime}=\varepsilon_{0}^{\prime}-\alpha \cdot \log (f)
$$

where $\varepsilon_{0}^{\prime}$ is the initial permittivity and $\alpha$ is the slope of the frequency dispersion. In this frequency range, the main contributions to the dielectric permittivity are generated by the crystalline lattice (intrinsic effect) and domain wall contributions, but also from nanometer-sized polar areas (both of extrinsic character). ${ }^{36,55-58}$ Hereby, extrinsic effects are, in most cases, responsible for the frequency dispersion in the sub-GHz range. The observed frequency dispersion for the largegrained sample shows the expected behavior, which is characteristic for a donor doped PZT ceramic. ${ }^{59}$ The reduction in grain size leads to a change in the frequency-dependent behavior of the relative permittivity. Figure 10(a) shows a comparison between a fine-grained $(0.3 \mu \mathrm{m})$ and a coarse-grained $(4.67 \mu \mathrm{m})$ PZT sample, where a difference in the slope of the frequency dependency is apparent. Comparable studies on $\mathrm{BaTiO}_{3}$ also show an increase in the slope $\alpha$ with a reduction of grain size from $\approx 10 \mu \mathrm{m}$ down to $\approx 1 \mu \mathrm{m}$ and a significantly increased permittivity in this grain size range. ${ }^{60-62}$ The authors attribute this to the change in the domain structure in $\mathrm{BaTiO}_{3}$, which consists exclusively of a lamellar $90^{\circ}$ domain structure for a grain size of $1 \mu \mathrm{m}$. According to Hoshina et al., the increase in permittivity at this grain size is due to the increase in dipole polarization, generated by $90^{\circ}$ domain wall vibrations. If the domain wall density now increases, a significant increase in the permittivity, as well as the frequency dependency can be expected with similar domain wall mobility. A comparable phenomenon is also generally observed for acceptor- and donor-doped PZT materials. ${ }^{63}$

A detailed representation of the grain size influence of $\varepsilon_{0}^{\prime}$ and $\alpha$ for both poled and unpoled samples is shown in Figs. 11(a) and 11(b). In the unpoled state, no significant change can be observed down to about $2 \mu \mathrm{m}$ in grain size. Below $2 \mu \mathrm{m}$, however, a continuous increase in permittivity occurs with decreasing grain size. A more significant effect can be observed for the logarithmic dispersion $\alpha$ for these grain sizes below $2 \mu \mathrm{m}$ [Fig. 11(b)], where the slope increases by a factor of two. The observed increase in $\varepsilon_{\text {unpol }}^{\prime}$ and $\alpha_{\text {unpol }}$ can be attributed to the change from a complex $3 \mathrm{D}$ configuration to a single lamellar structure and the increase in non- $180^{\circ}$ domain wall density as described earlier. With smaller grain sizes, which are directly correlated with smaller domain sizes, the polar ordering is reduced, and simultaneously the domain wall mobility increases. This effect is intensified by the decrease in unit cell distortion. A further reduction in grain size between $0.5 \mu \mathrm{m}$ and $0.25 \mu \mathrm{m}$ shows only minor changes in $\varepsilon_{0}^{\prime}$ and $\alpha$, which is likely due to the now dominating effect of lower unit cell distortion and the increase in volume around a non- $180^{\circ}$ domain wall that is affected by the domain wall itself.

For large grain sizes, Fig. 11(a) shows the expected picture of an increase in $\boldsymbol{\varepsilon}_{\text {pol }}^{\prime}$ for tetragonal compositions due to the reduction of the domain wall density during the polarization process, (a)

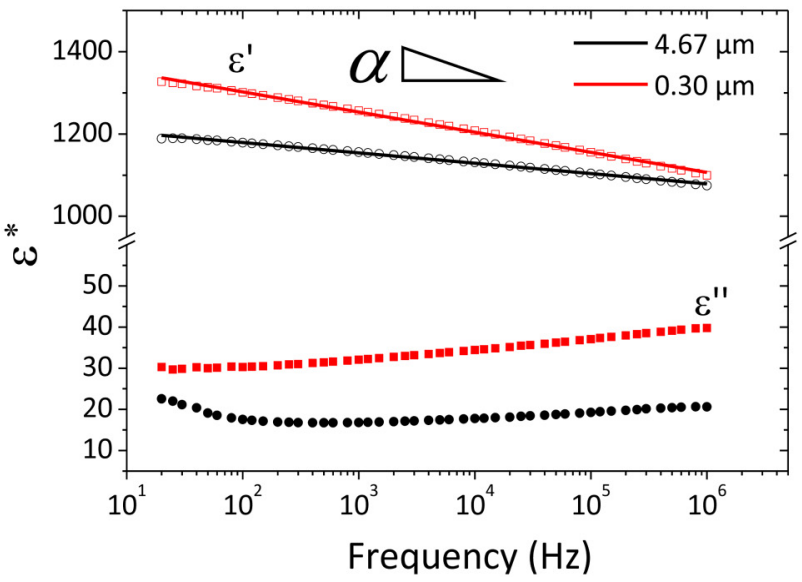

(b)
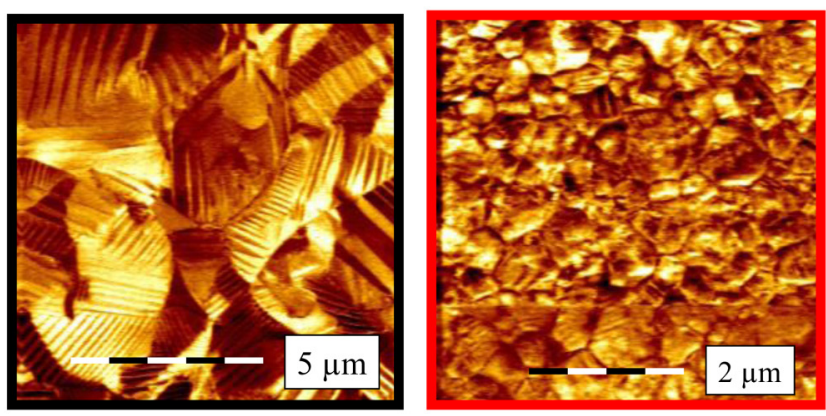

Grain size: $4.67 \mu \mathrm{m}$
Grain size: $0.30 \mu \mathrm{m}$

FIG. 10. (a) Real $\varepsilon^{\prime}$ and imaginary $\varepsilon^{\prime \prime}$ part of the dielectric permittivity for two selected grain sizes. Influence of the grain size and (b) PFM in-plane signal showing the corresponding domain structure. 
(a)

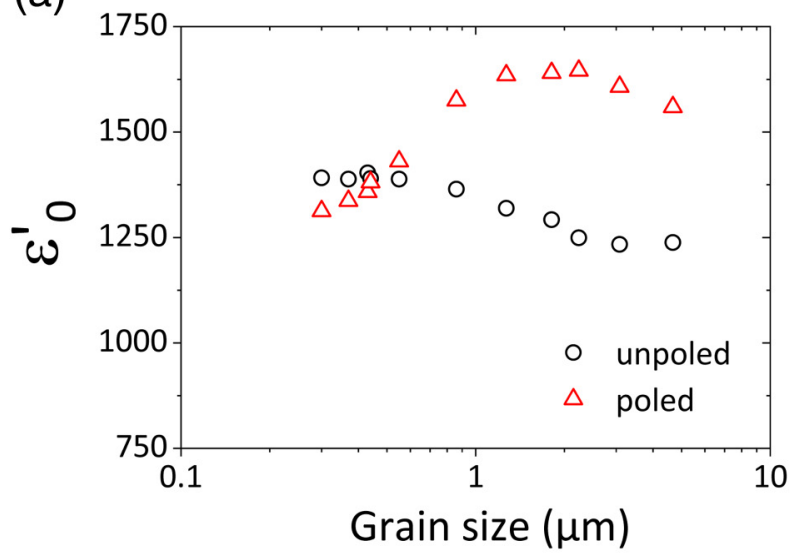

(b)

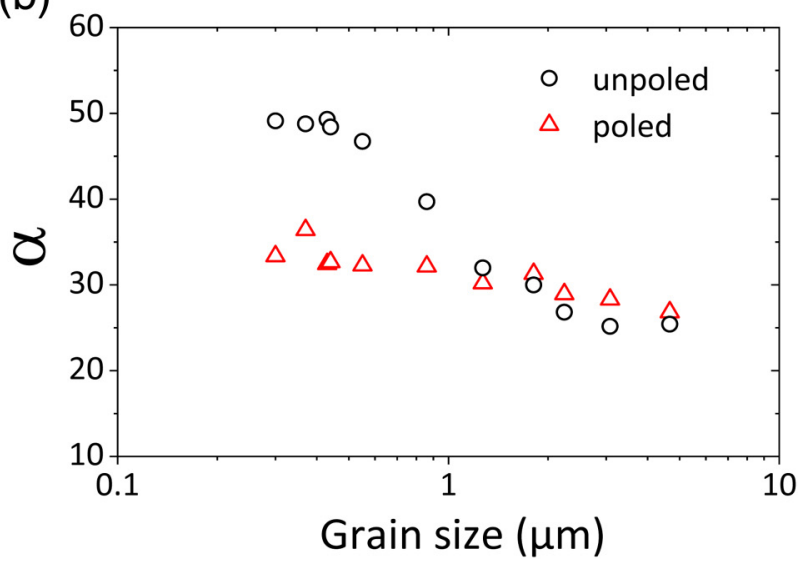

FIG. 11. Influence of the grain size on (a) $\varepsilon_{0}^{\prime}$ and (b) $\alpha$ for poled and unpoled samples.

resulting in a reduction in domain wall clamping and, thus, to an increase in the permittivity. ${ }^{59,64}$ Obviously, this has no influence on $\alpha$. For a grain size lower than $2 \mu \mathrm{m}$, however, the behavior of $\varepsilon_{p o l}^{\prime}$ and the gradient $\alpha$ inverts. At a grain size of $0.25 \mu \mathrm{m}, \varepsilon_{p o l}^{\prime}$ is even lower than $\varepsilon_{\text {unpol }}^{\prime}$ and $\alpha$ is reduced by around 30\% compared to the unpoled state. At very small grain sizes, a significant reduction in the distortion of the perovskite lattice and the tetragonal phase content is observed, combined with a change in the domain complexity. This interplay may lead to the observed change in the slope $\alpha$ and the decrease in permittivity due to the polarization process.

The temperature-dependent dielectric permittivity of unpoled PZT with different grain sizes, measured at $1 \mathrm{kHz}$ [Fig. 12(a)], displays a decrease in the maximum permittivity and a corresponding increase in the Curie temperature, $T_{c}$, with decreasing grain size. In contrast, Randall et al. ${ }^{15}$ reported that the grain size $(0.1-10 \mu \mathrm{m})$ does not influence the Curie temperature of Nb-doped PZT. Previous work showed that undoped PZT displays a larger shift in Curie temperature with decreasing grain size, which was argued to be due to a space-charge effect rather than a grain size effect. Okazaki and Nagata ${ }^{65}$ reported the effect of space charge on the ferroelectric-paraelectric phase transition temperature using $\mathrm{BaTiO}_{3}$ and La-doped PZT(65/35). It should be mentioned here that the space charge effect reported in these previous works was observed on electrically poled and aged samples. However, in our (a)

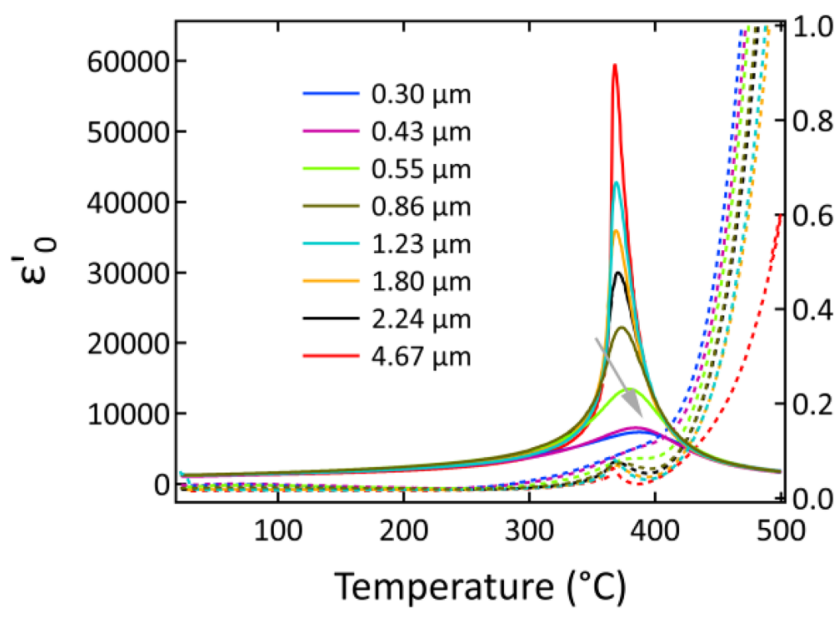

(b)

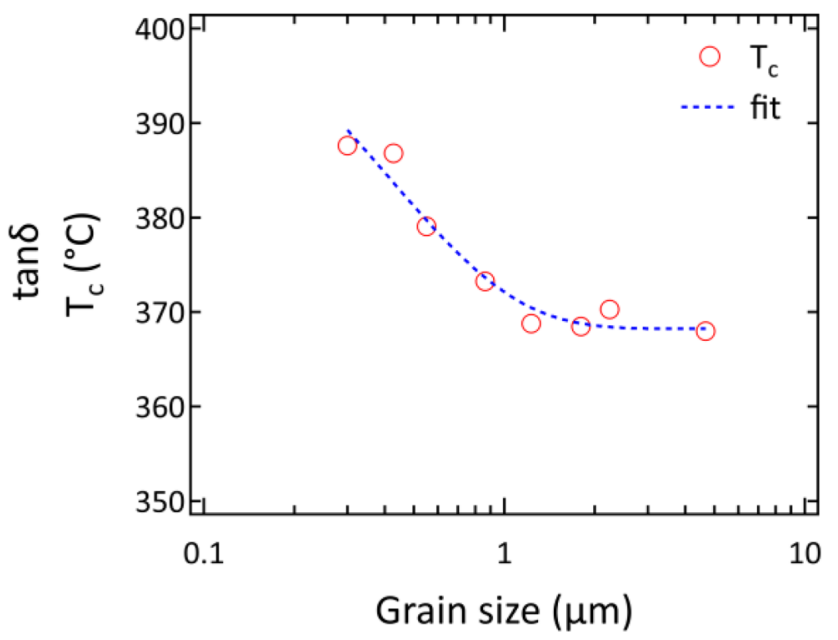

FIG. 12. (a) Temperature-dependent dielectric permittivity measured at $1 \mathrm{kHz}$ and (b) variation in Curie temperature, $T_{\mathrm{c}}$, as a function of grain size. 
case, the shift in $\mathrm{T}_{\mathrm{c}}$ is consistent for both unpoled and poled samples. It is known that the existence of space charge could give rise to significant internal bias fields during the poling process and consequently influences the measured macroscopic P-E/S-E loops. ${ }^{66}$ However, the fine-grained $(0.3 \mu \mathrm{m})$ PZT sample does not exhibit asymmetry in the P-E/S-E loops (Fig. 8). As such, a significant effect of space charge in this sample can be excluded. The influence of partial or full Schottky defects on $T_{c}$ in nonstoichiometric $\mathrm{BaTiO}_{3}$ has also been reported. ${ }^{67}$ Additionally, $\mathrm{T}_{\mathrm{c}}$ of non-stoichiometric $\mathrm{BaTiO}_{3}$ was found to be influenced by the oxygen partial pressure, that is, below $10^{-15}$ atm $(0.31 \mathrm{~Pa})$, the $T_{c}$ increases. The fine-grained $0.3 \mu \mathrm{m}$ and the $1.8 \mu \mathrm{m}$ samples were also investigated under vacuum conditions (Fig. S3 in the supplementary material). However, no significant variation in $T_{c}$ was observed under air and vacuum atmosphere.

In addition to the defect chemistry, the phase transition temperature can also be influenced by stresses, for example, hydrostatic, biaxial, and/or uniaxial stresses. ${ }^{68-70}$ For example, Schader et al. showed that the $\mathrm{T}_{\mathrm{c}}$ of single-crystal as well as polycrystalline $\mathrm{BaTiO}_{3}$, can be shifted to a higher temperature by applying uniaxial compressive stress. Bi-axial compressive stress is also found to have a similar influence on the phase transition temperatures. ${ }^{71}$ Previous studies have demonstrated that hydrostatic stress stabilizes the high temperature paraelectric cubic phase and, therefore, should result in a)

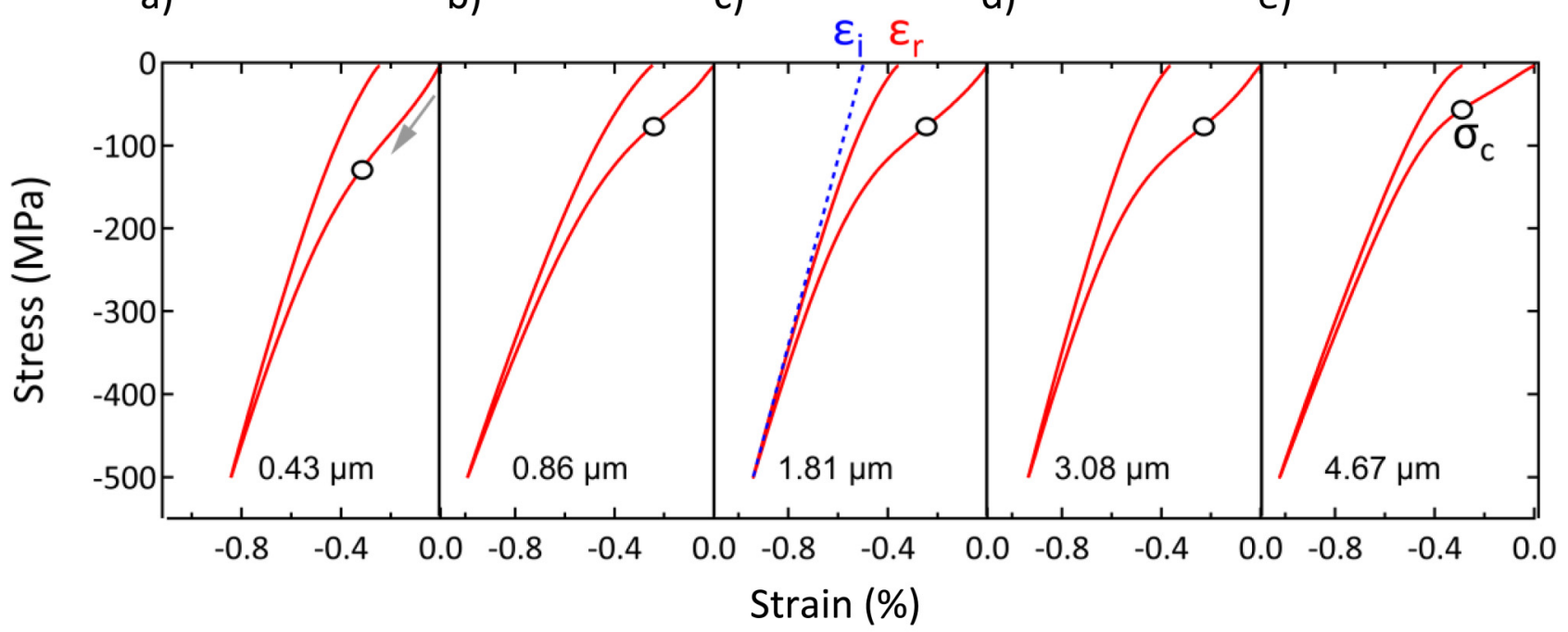

f)

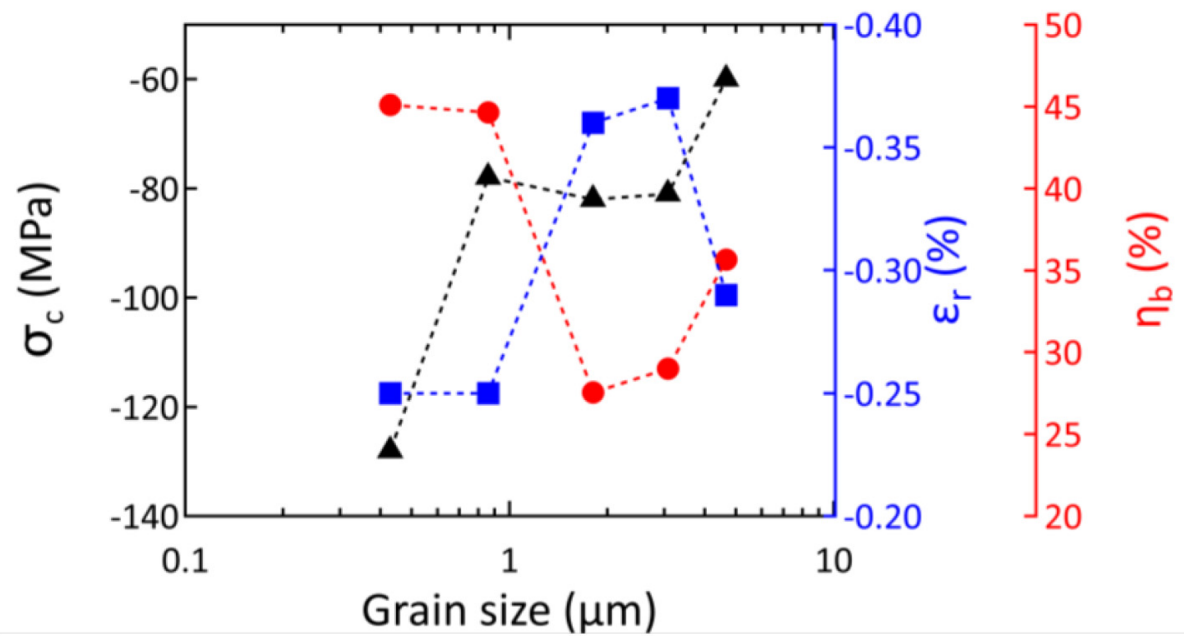

FIG. 13. (a)-(e) Macroscopic stress-strain measurements up to $-500 \mathrm{MPa}$, and (f) variation in coercive stress, remanent strain, and back-switching as a function of grain size. 
a decrease in the Curie temperature as well as increase the maximum permittivity. ${ }^{69,72,73}$ This indicates that the stress state in the current study is not purely hydrostatic and, rather, a complex stress state consisting of hydrostatic, extensional, and deviatoric stress components. As has been described above, the variation in grain size or domain wall density could induce a different degree of internal stress in the material. As such, it is possible that the higher temperature shift in $T_{c}$, observed in this work with decreasing grain size, is a complex combination of defect chemistry and the internal stress state related to the fine microstructures. Nevertheless, further investigations such as temperature-dependent permittivity with varying oxygen partial pressure can be useful to understand the possible influence of defects on $\mathrm{T}_{\mathrm{c}}$ in the composition studied here.

\section{Part III: Ferroelastic behavior}

The grain-size dependent mechanical behavior of PZT is shown in Fig. 13, displaying a ferroelastic response consistent with previous reports. ${ }^{35}$ Interestingly, ferroelastic parameters, that is, coercive stress, $\sigma_{\mathrm{c}}$, and remanent strain, $\varepsilon_{\mathrm{r}}$, determined from the stress-strain measurements, show variation with grain size. Similar to the coercive electric field $\left(\mathrm{E}_{\mathrm{c}}\right)$, the coercive stress was also found to be influenced by the variation in grain size, that is, $\sigma_{\mathrm{c}}$ increases with decreasing grain size. On the other hand, the remanent strain was found to increase up to $3 \mu \mathrm{m}$ and then subsequently decrease for the coarse-grained $4.67 \mu \mathrm{m}$ sample. Notably, the nonlinearity at the low-stress levels during mechanical unloading provides information on the extrinsic contribution to the ferroelastic response. The degree of back-switching, $\eta_{b}$, can be estimated by the parameter $1-\left(\varepsilon_{\mathrm{r}} / \varepsilon_{\mathrm{i}}\right)$, where $\varepsilon_{\mathrm{r}}$ is the remanent strain and $\varepsilon_{\mathrm{i}}$ is the $\mathrm{x}$ axis intersection of a linear fit of the linear region in the unloading curve. ${ }^{35}$ During unloading, the stress-strain loop shows nonlinearity due to domain back-switching at low-stress levels. In addition to the vacancy mediated domain pinning mechanism, the backswitching of non $-180^{\circ}$ domains is related to the intergranular residual mechanical and electrical fields in the polycrystal. Grains with an ideal orientation for ferroelastic switching are mechanically coupled to their neighboring grains, which will, therefore, experience a higher degree of intergranular elastic strain. After unloading, the elastically deformed grains will expand again, forcing a fraction of the switched domains back into their original state. As such, a greater intergranular residual stress may enhance domain back-switching. As can be seen in Fig. 13(f), the extent of back switching is maximum for the fine-grained samples up to $0.86 \mu \mathrm{m}$. On the other hand, samples with intermediate grain size (domain complexity) show the lowest extent of domain backswitching. This observation, in conjunction with the electric-field dependent structure, further highlights the importance of domain structure on the ferroelectric as well as on the ferroelastic response of bulk piezoelectric materials.

\section{CONCLUSIONS}

In general, complex 3D domain structures can be observed in grains significantly larger than $1 \mu \mathrm{m}$. In this range with decreasing grain size, however, the amount of non $-180^{\circ}$ domains increases due to the relation between grain size and domain size. Therefore, the non- $180^{\circ}$ domain switching with electric field increases and leads to higher $P_{\text {rem }}$ and $S_{\text {rem }}$. Due to the release of domain wall clamping effects, the small signal permittivity increases after poling for grain sizes above $1 \mu \mathrm{m} .{ }^{64}$ However, the frequency dependence is unchanged. By applying an electric field, the ferroelectric domains will realign along the poling direction, whereby the amount of domain walls is reduced, resulting in less domain clamping and, thus, higher permittivity.

Grain sizes below $1 \mu \mathrm{m}$ lead to rapidly increasing mechanical stresses, which are reflected in decreasing unit cell distortion and the increase in the non-tetragonal phase fractions. Increasing mechanical clamping with decreasing grain size increasingly hinders domain switching. Due to the decreasing unit cell distortion, the effect of domain switching is reduced, which leads to a decrease in polarization and strain behavior. The pronounced increase in $\mathrm{E}_{\mathrm{C}}$ also indicates higher mechanical clamping, resulting in higher switching energies and therefore less domain switching. The domain switching processes, which can be initiated by an applied electric field, are increasingly irreversible for grain sizes below $0.6 \mu \mathrm{m}$. For grain sizes below $1 \mu \mathrm{m}$, the frequency dependence of the permittivity decreases significantly after poling. This indicates high mechanical stresses and disorder, which influences the domains and domain walls and their mobility. These stresses lead to a clamped behavior after poling, which explains the steep decrease in electromechanical properties with decreasing grain sizes below $1 \mu \mathrm{m}$. The correlation between the change in domain configuration, increasing internal stresses, effects of poling on the crystal structure, and the macroscopic ferroelectric and ferroelastic properties allows a deeper understanding of size effects in polycrystalline donor doped PZT ceramics. Our work adds significant contributions to close the knowledge gap between technically applied polycrystalline PZT ceramics with grain sizes of $2-10 \mu \mathrm{m}$ and thin films with grain sizes well below $500 \mathrm{~nm}$.

\section{SUPPLEMENTARY MATERIAL}

See the supplementary material for more details on structural and dielectric characterization.

\section{ACKNOWLEDGMENTS}

The authors would like to thank the German Research Society (Deutsche Forschungsgemeinschaft, DFG) for Grant No. HI 1867/1-1. The beamtime at beamline P02.1 at the Deutsches Elektronensynchrotron (DESY, Hamburg, Germany) and the support from Dr. Martin Etter is greatly acknowledged. G.P. would like to thank Rodrigo P. Fernandes and Gerold A. Schneider from Hamburg University of Technology for the support for PFM measurements.

\section{DATA AVAILABILITY}

The data that support the findings of this study are available from the corresponding author upon request.

\section{REFERENCES}

${ }^{1}$ J. Rödel, W. Jo, K. T. P. Seifert, E.-M. Anton, T. Granzow, and D. Damjanovic, "Perspective on the development of lead-free piezoceramics," J. Am. Ceram. Soc. 92, 1153 (2009). 
${ }^{\mathbf{2}}$ M. Hinterstein, M. Hoelzel, J. Rouquette, J. Haines, J. Glaum, H. Kungl, and M. Hoffman, "Interplay of strain mechanisms in morphotropic piezoceramics," Acta Mater. 94, 319 (2015).

${ }^{3}$ M. Hinterstein, K.-Y. Lee, S. Esslinger, J. Glaum, A. J. Studer, M. Hoffman, and M. J. Hoffmann, "Determining fundamental properties from diffraction: Electric field induced strain and piezoelectric coefficient," Phys. Rev. B 99, 174107 (2019). ${ }^{4}$ S. Eßlinger, P. Neumeister, A. Schönecker, M. Hoffman, A. Studer, and M. Hinterstein, "In situ neutron diffraction studies on poling of the hard PZT ceramic PIC181," Adv. Eng. Mater. 21, 1900159 (2019).

${ }^{5}$ M. Oldenkotte, H. Kungl, R. Eichel, K. A. Schönau, M. Kühlein, T. Bernard, M. J. Hoffmann, and M. Hinterstein, "Influence of $\mathrm{PbO}$ stoichiometry on the properties of PZT ceramics and multilayer actuators," J. Am. Ceram. Soc. 102, 5401 (2019).

${ }^{6}$ D. Ghosh, A. Sakata, J. Carter, P. A. Thomas, H. Han, J. C. Nino, and J. L. Jones, "Domain wall displacement is the origin of superior permittivity and piezoelectricity in $\mathrm{BaTiO}_{3}$ at intermediate grain sizes," Adv. Funct. Mater. 24, 885 (2014).

${ }^{7}$ W. Cao and C. A. Randall, "Grain size and domain size relations in bulk ceramic ferroelectric materials," J. Phys. Chem. Solids 57, 1499 (1996).

${ }^{8}$ C. Sakaki, B. L. Newalkar, S. Komarneni, and K. Uchino, "Grain size dependence of high power piezoelectric characteristics in $\mathrm{Nb}$ doped lead zirconate titanate oxide ceramics," Jpn. J. Appl. Phys. 40, 6907 (2001).

${ }^{9} \mathrm{~K}$. Kinoshita and A. Yamaji, "Grain-size effects on dielectric properties in barium titanate ceramics,” J. Appl. Phys. 47, 371 (1976).

${ }^{10} \mathrm{~V}$. Buscaglia and C. A. Randall, "Size and scaling effects in barium titanate: An overview," J. Eur. Ceram. Soc. 40, 3744 (2020).

${ }^{11}$ T. M. Shaw, S. Trolier-McKinstry, and P. C. McIntyre, "The properties of ferroelectric films at small dimensions," Annu. Rev. Mater. Sci. 30, 263 (2000).

${ }^{12}$ K. A. Schoenau, L. A. Schmitt, M. Knapp, H. Fuess, R.-A. Eichel, H. Kungl, and M. J. Hoffmann, "Nanodomain structure of $\mathrm{Pb}\left[\mathrm{Zr}_{1-\mathrm{x}} \mathrm{Ti}_{\mathrm{x}}\right] \mathrm{O}_{3}$ at its morphotropic phase boundary: Investigations from local to average structure," Phys. Rev. B 75, 184117 (2007)

${ }^{13}$ M. Hinterstein, K. A. Schoenau, J. Kling, H. Fuess, M. Knapp, H. Kungl, and M. J. Hoffmann, "Influence of lanthanum doping on the morphotropic phase boundary of lead zirconate titanate," J. Appl. Phys. 108, 024110 (2010).

${ }^{14} \mathrm{G}$. Arlt and K. Okada, "Twinning in ferroelectric and ferroelastic ceramics: Stress relief," J. Mater. Sci. 25, 2655 (1990).

${ }^{15}$ C. A. Randall, N. Kim, J. Kucera, W. Cao, and T. R. Shrout, "Intrinsic and extrinsic size effects in fine-grained morphotropic-phase-boundary lead zirconate titanate ceramics," J. Am. Ceram. Soc. 81, 677 (1998).

${ }^{16}$ A. S. Sonin and B. A. Strukov, Einführung in Die Ferroelektrizität (Vieweg, 1974).

${ }^{17}$ T. Mitsui, I. Tatsuzaki, and E. Nakamura, An Introduction to the Physics of Ferroelectrics (Gordon and Breach Science Publishers, New York, 1976).

${ }^{18}$ I. MacLaren, L. A. Schmitt, H. Fuess, H. Kungl, and M. J. Hoffmann, "Experimental measurement of stress at a four-domain junction in lead zirconate titanate," J. Appl. Phys. 97, 094102 (2005).

${ }^{19} \mathrm{R}$. Waser, U. Böttger, and S. Tiedke, Polar Oxides: Properties, Characterization, and Imaging (Wiley, 2006).

${ }^{\mathbf{2 0}} \mathrm{G}$. Arlt, "The role of domain walls on the dielectric, elastic and piezoelectric properties of ferroelectric ceramics," Ferroelectrics 76, 451 (1987).

${ }^{21} \mathrm{G}$. Arlt and P. Sasko, "Domain configuration and equilibrium size of domains in $\mathrm{BaTiO}_{3}$ ceramics," J. Appl. Phys. 51, 4956 (1980).

${ }^{22}$ E. K. W. Goo, R. K. Mishra, and G. Thomas, "Electron microscopy study of the ferroelectric domains and domain wall structure in $\mathrm{PbZr}_{0.52} \mathrm{Ti}_{0.48} \mathrm{O}_{3}$," J. Appl. Phys. 52, 2940 (1981).

${ }^{23}$ W. Cao and L. Cross, "Theory of tetragonal twin structures in ferroelectric perovskites with a first-order phase transition," Phys. Rev. B 44, 5 (1991).

${ }^{24}$ U. Lange, Einfluß Der Korngröße Auf Die Morphotrope Phasengrenze in Sol-Gel Abgeleiteten Nd-Dotierten PZT-Keramiken (Universität Würzburg, 2003).

${ }^{25}$ M. J. Hoffmann, M. Hammer, A. Endriss, and D. C. Lupascu, "Correlation between microstructure, strain behavior, and acoustic emission of soft PZT ceramics," Acta Mater. 49, 1301 (2001).
${ }^{26} \mathrm{G}$. Auer, H. Günnel, F. Hipler, M. J. Hoffmann, S. Wagner, and H. Kungl, "Fine-particulate lead zirconium titanates zirconium titanate hydrates and zirconium titanates and method for production thereof," U.S. patent US8080230B2 (Dec. 20, 2011).

${ }^{27}$ A. P. Singh, S. K. Mishra, D. Pandey, C. D. Prasad, and R. Lal, "Low-temperature synthesis of chemically homogeneous lead zirconate titanate (PZT) powders by a semi-wet method," J. Mater. Sci. 28, 5050 (1993).

${ }^{\mathbf{2 8}}$ T. R. Shrout, P. Papet, S. Kim, and G.-S. Lee, "Conventionally prepared submicrometer lead-based perovskite powders by reactive calcination," J. Am. Ceram. Soc. 73, 1862 (1990).

${ }^{29}$ R. B. Atkin and R. M. Fulrath, "Point defects and sintering of lead zirconatetitanate,” J. Am. Ceram. Soc. 54, 265 (1971).

${ }^{30}$ M. Herklotz, F. Scheiba, M. Hinterstein, K. Nikolowski, M. Knapp, A.-C. Dippel, L. Giebeler, J. Eckert, and H. Ehrenberg, "Advances in in situ powder diffraction of battery materials: A case study of the new beamline P02.1 at DESY, Hamburg," J. Appl. Crystallogr. 46, 1117 (2013).

${ }^{31}$ A. Dippel, H. Liermann, J. T. Delitz, P. Walter, H. Schulte-Schrepping, O. H. Seeck, and H. Franz, "Beamline P02.1 at PETRA III for high-resolution and high-energy powder diffraction," J. Synchrotr. Radiat. 22, 675 (2015).

${ }^{32}$ H. Choe, S. Gorfman, M. Hinterstein, M. Ziolkowski, M. Knapp, S. Heidbrink, M. Vogt, J. Bednarcik, A. Berghäuser, H. Ehrenberg, and U. Pietsch, "Combining high time and angular resolutions: Time-resolved X-ray powder diffraction using a multi-channel analyser detector," J. Appl. Crystallogr. 48, 970 (2015).

${ }^{33}$ K.-Y. Lee, X. Shi, N. Kumar, M. Hoffman, M. Etter, S. Checchia, J. Winter L. Lemos da Silva, D. Seifert, M. Hinterstein, L. L. da Silva, D. Seifert, and M. Hinterstein, "Electric-field-induced phase transformation and frequencydependent behavior of bismuth sodium titanate-barium titanate," Materials 13, 1054 (2020).

${ }^{34}$ L. Lutterotti, S. Matthies, D. Chateigner, S. Ferrari, and J. Ricote, "Rietveld texture and stress analysis of thin films by X-ray diffraction," Mater. Sci. Forum 408-412, 1603 (2002).

${ }^{35}$ K. G. Webber, E. Aulbach, T. Key, M. Marsilius, T. Granzow, and J. Rödel, "Temperature-dependent ferroelastic switching of soft lead zirconate titanate," Acta Mater. 57, 4614 (2009).

${ }^{36} \mathrm{M}$. E. Lines and A. M. Glass, Principles and Applications of Ferroelectrics and Related Materials (Oxford University Press, Clarendon, 1977).

${ }^{37} \mathrm{~T}$. Mitsui and J. Furuichi, "Domain structure of Rochelle salt and $\mathrm{KH}_{2} \mathrm{PO}_{4}$," Phys. Rev. 90, 193 (1953).

${ }^{38} \mathrm{C}$. Kittel, "Theory of the structure of ferromagnetic domains in films and small particles," Phys. Rev. 70, 965 (1946).

${ }^{39}$ U. J. Sutter, Domäneneffekte in Ferroelektrischen PZT-Keramiken (Universitat Karlsruhe, 2006)

${ }^{40} \mathrm{G}$. Picht, Einfluss Der Korngröße Auf Ferroelektrische Eigenschaften Dotierter $\mathrm{Pb}\left(\mathrm{Zr}_{1-\mathrm{X}} \mathrm{Ti}_{x}\right) \mathrm{O}_{3}$ Materialien (KIT Scientific Publishing, 2013).

${ }^{41}$ G. Fraysse, A. Al-Zein, J. Haines, J. Rouquette, V. Bornand, P. Papet, C. Bogicevic, and S. Hull, "Competing order parameters in the $\mathrm{Pb}\left(\mathrm{Zr}_{1-\mathrm{x}} \mathrm{Ti}_{\mathrm{x}}\right) \mathrm{O}_{3}$ solid solution at high pressure," Phys. Rev. B 84, 1 (2011).

${ }^{42}$ F. Birch, "Finite elastic strain of cubic crystals," Phys. Rev. 71, 809 (1947).

${ }^{43}$ G. Esteves, C. M. Fancher, S. Röhrig, G. A. Maier, J. L. Jones, and M. Deluca, "Electric-field-induced structural changes in multilayer piezoelectric actuators during electrical and mechanical loading," Acta Mater. 132, 96 (2017).

${ }^{44}$ M. Hinterstein, J. Rouquette, J. Haines, P. Papet, J. Glaum, M. Knapp, J. Eckert, and M. Hoffman, "Structural contribution to the ferroelectric fatigue in lead zirconate titanate ceramics," Phys. Rev. B 90, 094113 (2014).

${ }^{45} \mathrm{M}$. Hinterstein, J. Rouquette, J. Haines, P. Papet, M. Knapp, J. Glaum, and H. Fuess, "Structural description of the macroscopic piezo- and ferroelectric properties of lead zirconate titanate," Phys. Rev. Lett. 107, 077602 (2011).

${ }^{46} \mathrm{H}$. Kungl, Dehnungsverhalten von Morphotropem PZT (Universitat Karlsruhe, 2005).

${ }^{47} \mathrm{H}$. Kungl and M. J. Hoffmann, "Effects of sintering temperature on microstructure and high field strain of niobium-strontium doped morphotropic lead zirconate titanate," J. Appl. Phys. 107, 054111 (2010). 
${ }^{48}$ T. Yamamoto, "Optimum preparation methods for piezoelectric ceramics and their evaluation,” Am. Ceram. Soc. Bull. 71, 96 (1992).

${ }^{49}$ W. Wersing, W. Heywang, H. Beige, and H. Thomann, "The role of ferroelectricity for piezoelectric materials," in Piezoelectricity (Springer-Verlag, Berlin, Berlin, Heidelberg, 2008), Vol. 114, pp. 37-87.

${ }^{50}$ A. Y. Dantsiger, N. V. Dergunova, S. I. Dudkina, and E. G. Fesenko, "Ferroelectric solid solutions with high piezoelectric characteristics," Ferroelectrics 132, 213 (1992).

${ }^{51}$ A. Y. Dantsiger, N. V. Dergunova, S. I. Dudkina, O. N. Razumovskaya, L. A. Shilkina, and V. A. Servuli, "Interdependences among crystallochemical, structural and electrophysical parameters of ferroelectric solid solutions," Ferroelectrics 132, 207 (1992).

${ }^{52}$ E. G. Fesenko, A. Y. Dantsiger, L. A. Resnitchenko, and M. F. Kupriyanov, "Composition-structure-properties dependences in solid solutions on the basis of lead-zirconate-titanate and sodium niobate," Ferroelectrics 41, 137 (1982).

${ }^{53}$ G. Helke and K. Lubitz, "Piezoelectric PZT Ceramics," in Piezoelectricity (Springer Berlin Heidelberg, Berlin, Heidelberg, 2008), pp. 89-130.

${ }^{54} \mathrm{~L}$. Jin, Broadband Dielectric Response in Hard and Soft PZT Understanding Softening and Hardening Mechanisms (EPFL, 2011).

${ }^{55}$ A. K. Tagantsev, L. E. Cross, and J. Fousek, Domains in Ferroic Crystals and Thin Films (Springer New York, New York, NY, 2010).

${ }^{\mathbf{5 6}} \mathrm{O}$. Kersten and G. Schmidt, "Dielectric dispersion in PZT ceramics," Ferroelectrics 67, 191 (1986).

${ }^{57} \mathrm{G}$. Arlt, U. Böttger, and S. Witte, "Dielectric dispersion of ferroelectric ceramics and single crystals at microwave frequencies," Ann. Phys. 506, 578 (1994).

${ }^{58}$ M. P. McNeal, S.-J. Jang, and R. E. Newnham, "The effect of grain and particle size on the microwave properties of barium titanate $\left(\mathrm{BaTiO}_{3}\right)$," J. Appl. Phys. 83, 3288 (1998)

${ }^{59} \mathrm{~V}$. Porokhonskyy and D. Damjanovic, "Domain wall contributions in $\mathrm{Pb}(\mathrm{Zr}, \mathrm{Ti}) \mathrm{O}_{3}$ ceramics at morphotropic phase boundary: A study of dielectric dispersion," Appl. Phys. Lett. 96, 242902 (2010).

${ }^{60}$ Y.-K. Choi, T. Hoshina, H. Takeda, T. Teranishi, and T. Tsurumi, "Effects of oxygen vacancies and grain sizes on the dielectric response of $\mathrm{BaTiO}_{3}$," Appl. Phys. Lett. 97, 212907 (2010).
${ }^{61}$ T. Hoshina, K. Takizawa, J. Li, T. Kasama, H. Kakemoto, and T. Tsurumi, "Domain size effect on dielectric properties of barium titanate ceramics," Jpn. J. Appl. Phys. 47, 7607 (2008).

${ }^{62}$ T. Hoshina, Y. Kigoshi, S. Hatta, T. Teranishi, H. Takeda, and T. Tsurumi, "Size effect and domain-wall contribution of barium titanate ceramics," Ferroelectrics 402, 29 (2010).

${ }^{63}$ D. Damjanovic, N. Klein, J. Li, and V. Porokhonskyy, "What can be expected from lead-free piezoelectric materials?," Funct. Mater. Lett. 03, 5 (2010).

${ }^{64}$ A. V. Turik, M. F. Kupriyanov, E. N. Sidorenko, and S. M. Zaitsev, "Behavior of piezoceramics of type $\mathrm{Pb}\left(\mathrm{Zr}_{\mathrm{x}} \mathrm{Ti}_{1-\mathrm{x}}\right) \mathrm{O}_{3}$ near the region of morphotropic transition," Sov. Phys. Tech. Phys. 25, 1251 (1980).

${ }^{65} \mathrm{~K}$. Okazaki and K. Nagata, "Effects of grain size and porosity on electrical and optical properties of PLZT ceramics," J. Am. Ceram. Soc. 56, 82 (1973).

${ }^{66}$ Y. A. Genenko, "Space-charge mechanism of aging in ferroelectrics: An analytically solvable two-dimensional model," Phys. Rev. B 78, 214103 (2008).

${ }^{67}$ S. Lee, Z.-K. Liu, M.-H. Kim, and C. A. Randall, "Influence of nonstoichiometry on ferroelectric phase transition in $\mathrm{BaTiO}_{3}$," J. Appl. Phys. 101, 054119 (2007).

${ }^{68} \mathrm{H}$. Jaffe, D. Berlincourt, and J. M. McKee, "Effect of pressure on the Curie temperature of polycrystalline ceramic barium titanate," Phys. Rev. 105, 57 (1957).

${ }^{69} \mathrm{~W}$. J. Merz, "The effect of hydrostatic pressure on the curie point of barium titanate single crystals," Phys. Rev. 78, 52 (1950).

${ }^{\mathbf{7 0}}$ F. H. Schader, E. Aulbach, K. G. Webber, and G. A. Rossetti, "Influence of uniaxial stress on the ferroelectric-to-paraelectric phase change in barium titanate," J. Appl. Phys. 113, 174103 (2013).

${ }^{71} \mathrm{P}$. W. Forsbergh, "Effect of a two-dimensional pressure on the Curie point of barium titanate," Phys. Rev. 93, 686 (1954).

${ }^{72} \mathrm{~J}$. Klimowski, "Effect of high hydrostatic pressure on the dielectric properties of $\mathrm{BaTiO}_{3}$ single crystals," Phys. Status Solidi 2, 456 (1962).

${ }^{73}$ G. A. Rossetti, L. E. Cross, and K. Kushida, "Stress induced shift of the Curie point in epitaxial $\mathrm{PbTiO}_{3}$ thin films,” Appl. Phys. Lett. 59, 2524 (1991). 